\title{
Simulations of Lithium-Magnetite Electrodes Incorporating Phase Change
}

Kevin W. Knehr ${ }^{1}$, Christina A. Cama², Nicholas W. Brady ${ }^{1}$, Amy C. Marschilok ${ }^{2,4}$, Kenneth J.

Takeuchi $^{2,4}$, Esther S. Takeuchi ${ }^{2,3,4}$ and Alan C. West ${ }^{1 *}$

${ }^{1}$ Department of Chemical Engineering,

Columbia University, New York, NY 10027

${ }^{2}$ Department of Chemistry

Stony Brook University, Stony Brook, NY 11794

${ }^{3}$ Energy Sciences Directorate

Brookhaven National Laboratory, Upton, NY 11973

${ }^{4}$ Department of Materials Science and Engineering

Stony Brook University, Stony Brook, NY 11794

Submitted with Revisions as a Technical Paper to

Electrochimica Acta

March, 2017

*Corresponding Author: e-mail: acw7@ columbia.edu; Phone: 1-212-854-4452

(C) 2017. This manuscript version is made available under the Elsevier user license http://www.elsevier.com/open-access/userlicense/1.0/ 


\section{Abstract}

The phase changes occurring in magnetite $\left(\mathrm{Fe}_{3} \mathrm{O}_{4}\right)$ during lithiation and voltage recovery experiments are modeled using a model that simulates the electrochemical performance of a $\mathrm{Fe}_{3} \mathrm{O}_{4}$ electrode by coupling the lithium transport in the agglomerate and nano-crystal lengthscales to thermodynamic and kinetic expressions. Phase changes are described using kinetic expressions based on the Avrami theory for nucleation and growth. Simulated results indicate that the slow, linear voltage change observed at long times during the voltage recovery experiments can be attributed to a slow phase change from $\alpha-\mathrm{Li}_{\mathrm{x}} \mathrm{Fe}_{3} \mathrm{O}_{4}$ to $\beta$ - $\mathrm{Li}_{4} \mathrm{Fe}_{3} \mathrm{O}_{4}$. In addition, the long voltage plateau at $\sim 1.2 \mathrm{~V}$ observed during lithiation of electrodes is attributed to conversion from $\alpha-\mathrm{Li}_{\mathrm{x}} \mathrm{Fe}_{3} \mathrm{O}_{4}$ to $\gamma-\left(4 \mathrm{Li}_{2} \mathrm{O}+3 \mathrm{Fe}\right)$. Simulations for the lithiation of 6 and $32 \mathrm{~nm}$ $\mathrm{Fe}_{3} \mathrm{O}_{4}$ suggest the rate of conversion to $\gamma-\left(4 \mathrm{Li}_{2} \mathrm{O}+3 \mathrm{Fe}\right)$ decreases with decreasing crystal size. Keywords

Nucleation and growth; voltage recovery; current interrupt; lithium-ion batteries; Avrami 


\section{Introduction}

Two major factors limiting the widespread use of electric vehicles are the size and cost of the lithium-ion batteries used in the power system. To address these issues, next-generation batteries must contain active materials with high specific energy ( $\mathrm{Wh} \mathrm{L}^{-1}$ or $\mathrm{Wh}^{-1}$ ), which can meet the required design specifications with smaller quantities of material. Currently, the specific energies of commercially available lithium-ion battery electrodes are limited by relatively low theoretical capacities - 140 to $200 \mathrm{mAh} \mathrm{g}^{-1}$ and $370 \mathrm{mAh} \mathrm{g}^{-1}$ for positive and negative electrode materials, respectively $[1,2]$. These materials have low capacities because they can only accept $\sim 1$ mole of lithium per mole of host material (e.g., $\mathrm{C}_{6}, \mathrm{CoO}_{2}$, and $\mathrm{FePO}_{4}$ ). In an effort to expand the capacity of battery electrodes, new compounds are being investigated which undergo multiple electron transfers (MET) and can accommodate multiple moles of lithium per mole of host material. These compounds include metal oxides, fluorides, oxyfluorides, nitrides, and sulfides [3-9]. Unlike commercial lithium-ion electrode materials, which store and release energy through a (de)intercalation reaction, the MET compounds can undergo conversion reactions, which result in the structural rearrangement and phase change of the host material. The kinetics of formation and reversibility of these phase changes are important factors dictating the applicability of these new materials.

Among the new set of compounds, magnetite $\left(\mathrm{Fe}_{3} \mathrm{O}_{4}\right)$ is of particular interest due to its low cost, safety, and high theoretical capacity $\left(926 \mathrm{mAh} \mathrm{g}^{-1}\right)$, which is associated with its ability to accommodate 8 moles of lithium per mole of $\mathrm{Fe}_{3} \mathrm{O}_{4}$ [10-15]. During lithiation, magnetite first undergoes an intercalation process which results in the structural rearrangement of the material from an inverse spinel to a rock-salt-like structure [16-20]. Upon further lithiation, magnetite undergoes a conversion process to $\mathrm{Li}_{2} \mathrm{O}$ and $\mathrm{Fe}$ metal [21-24]. Until recently, the performance of 
magnetite was limited by slow solid-state transport of lithium ions through the close-packed structure of the material. However, nanosizing has been utilized to shorten the path length for lithium ion diffusion, which has improved the rate capability and increased the utilization of the active material [13-15, 25-27]. Further improvements in rate capability and utilization have been obtained using alternative electrode synthesis methods that reduce agglomeration of the nanocrystals $[28,29]$. Despite these improvements, it is still difficult to obtain the theoretical capacity of $\mathrm{Fe}_{3} \mathrm{O}_{4}$, especially during cycling. Recently, investigations of the (de)lithiation process using synchrotron X-ray and transmission electron microscopy techniques have suggested that the poor capacity is caused by an inability to fully convert from $\mathrm{Li}_{2} \mathrm{O}$ and $\mathrm{Fe}$ metal into the inverse-spinel phase $\left(\mathrm{Fe}_{3} \mathrm{O}_{4}\right)$ during delithiation [21, 24]. This suggests that further improvements in performance may result from a better understanding of the kinetics of structural rearrangement and phase change within the material.

This work seeks to complement recent experimental investigations by modeling the phase changes occurring within magnetite during lithiation and voltage recovery. In the battery field, modeling of phase change has been done in other materials (e.g. $\mathrm{FePO}_{4}$ and $\mathrm{FeF}_{2}$ ) using phasefield theory, which implements the Cahn-Hilliard equation to describe the concentration distribution of $\mathrm{Li}^{+}$within a crystal [30-34]. Phase-field modeling is capable of simulating phaseseparation of materials into regions of high- and low-levels of lithiation by calculating the distribution of $\mathrm{Li}^{+}$which minimizes the free energy of the crystal. The concentration distributions agree well with experimental observations; however, the results are highly dependent on the use of a representation of the free energy of the system (often arising from regular solution theory and developed based on experimental observations), which often results in poor agreement between simulations and electrochemical performance data [33-37]. Other attempts to simulate 
the electrochemical performance of a material which undergoes phase change have utilized a "shrinking-core" model, which tracks the boundary separating the high- and low-lithium phases as it progresses from the surface of a crystal to the center during lithiation [38-40]. These models agree well with electrochemical data; however, they often only simulate the battery during lithiation of the electrode because modeling the subsequent delithiation is difficult due to the existence of multiple moving boundaries. In addition, shrinking-core models assume that both phases (high- and low- lithium) are already present at the start of the simulation. Therefore, they do not provide kinetic descriptions of the initial formation of the highly concentrated phase.

In this work, we seek to simulate the phase changes within magnetite during lithiation by incorporating the kinetics of nucleation and growth of new phases into a previously developed model [41-43]. The previously developed model, which did not include phase change, simulates the electrochemical performance of $\mathrm{a} \mathrm{Fe}_{3} \mathrm{O}_{4}$ electrode by coupling the lithium transport in the agglomerate and crystal length-scales to thermodynamic and kinetic expressions. In previous work, the model without phase change was able to capture the electrochemical performance of an electrode at low levels of lithiation, where $\mathrm{Fe}_{3} \mathrm{O}_{4}$ undergoes an intercalation process [42]. To expand our understanding to higher levels of lithiation, the formation of new phases are incorporated into the previously developed model using kinetic expressions inspired by the Avrami theory for nucleation and growth [44-46]. Herein, simulations with phase change are used to explain the behavior of electrodes with "small" ( $\sim 6 \mathrm{~nm})$ and "large" (32 nm) crystals during lithiation and voltage recovery experiments.

\section{Experimental}

Nanocrystalline magnetite, $\mathrm{Fe}_{3} \mathrm{O}_{4}$, was synthesized using a co-precipitation approach, utilizing aqueous solutions of iron (III) chloride hexahydrate, iron (II) chloride hexahydrate, and 
base according to a previously reported method $[14,15]$. Larger sized nanocrystalline magnetite, $\sim 32 \mathrm{~nm}$, was purchased from Alfa Aesar. X-ray diffraction data was collected using a Rigaku Smart $\mathrm{Lab}$ diffractometer with $\mathrm{Cu} \mathrm{K} \alpha$ radiation. The crystallite sizes of the $\mathrm{Fe}_{3} \mathrm{O}_{4}$ powders were calculated by applying the Scherrer equation to the FWHM of the (311) peak [47]. An instrumental broadening correction was applied using $\mathrm{a} \mathrm{LaB}_{6}$ standard.

Electrodes were prepared using magnetite, carbon, and polyvinylidene fluoride binder coated onto an aluminum foil substrate. Electrochemical tests were performed using two electrode coin-type experimental cells with lithium metal anodes and $1 \mathrm{M} \mathrm{LiPF} 6$ in dimethyl carbonate:ethylene carbonate electrolyte (1:1 by volume). The electrode was comprised by weight of $90 \% \mathrm{Fe}_{3} \mathrm{O}_{4}, 5 \%$ acetylene carbon black, and 5\% PVDF. For electrodes comprised of 6 and $32 \mathrm{~nm}$ crystals, lithiation was conducted under a $\mathrm{C} / 200$ rate to $0.5,1.0,1.5,2.0,2.5,3.0,3.5$ and 4.0 electron equivalents per $\mathrm{Fe}_{3} \mathrm{O}_{4}$ and then allowed to rest under open circuit conditions for up to 30 days. For electrodes comprised of $8 \mathrm{~nm}$ crystals, similar experiments were conducted to 0.5, 1.0, 1.5, 2.0, 2.5, 3.25, 3.5, 4.0, 4.5, 5.0, 6.0, 7.0, and 8.0 electron equivalents per $\mathrm{Fe}_{3} \mathrm{O}_{4}$. All electrochemical testing was conducted at $30^{\circ} \mathrm{C}$.

\section{Kinetics of Phase Change}

This section describes the generic approach used to model the rearrangement of a material from " $a$ " to " $b$," where $a$ and $b$ are unique phases of the same host material. Both $a$ and $b$ contain the same number of host atoms (e.g., for a host material of $\mathrm{Fe}_{3} \mathrm{O}_{4}$ both phases contain 3 Fe and $4 \mathrm{O}$ ), but they differ in the arrangement of those atoms and in the concentration of solidstate lithium within the phases, designated as $c_{a}$ and $c_{b}$. At equilibrium, both phases have the same chemical potential and well-defined concentrations of solid-state lithium, whereby $c_{a}{ }^{*}<c_{b}{ }^{*}$ with the $*$ denoting equilibrium values (see Figure 1 ). Because both phases are at the same 
chemical potential, a plateau is observed in the equilibrium voltage, whereby the host material has the same equilibrium voltage at all solid-state lithium concentrations between $c_{a}{ }^{*}$ and $c_{b}{ }^{*}$ [39]. In this region between $c_{a}{ }^{*}$ and $c_{b}{ }^{*}$, the equilibrium structure of the host material corresponds to a fraction of phase $a$ at concentration $c_{a}{ }^{*}$ and a fraction of phase $b$ at concentration $c_{b}{ }^{*}$. Under equilibrium conditions, the fractions of $a$ and $b$ can be determined from a mass balance. Under non-equilibrium conditions, such as the discharge of an electrode, the formation of phase $b$ must be described by a kinetic process. If the formation of phase $b$ is instantaneous, the kinetic process can be described by the following equation:

$$
\mathrm{Li}_{\mathrm{a}} \Gamma_{\mathrm{a}}+(\mathrm{b}-\mathrm{a}) \mathrm{Li}^{+}+(\mathrm{b}-\mathrm{a}) \mathrm{e}^{-} \rightarrow \mathrm{Li}_{\mathrm{b}} \Gamma_{\mathrm{b}}
$$

where $\mathrm{Li}_{\mathrm{a}} \Gamma_{\mathrm{a}}$ and $\mathrm{Li}_{\mathrm{b}} \Gamma_{\mathrm{b}}$ are the equilibrium phases of $a$ and $b$, respectively, and $\Gamma_{\mathrm{a}}$ and $\Gamma_{\mathrm{b}}$ represent the arrangement of the atoms in the host material in phases $a$ and $b$, respectively. During lithiation of a material with instantaneous formation of phase $b$, the voltage is practically constant between $c_{a}{ }^{*}$ and $c_{b}{ }^{*}$ because Eq. 1 does not depend on the total solid-state lithium concentration.

In actuality, instantaneous formation of phase $b$ is only an ideal case that does not apply to all systems or at every operating condition. Therefore, a kinetic description is needed for the non-instantaneous formation of phase $b$ (from $a$ ). In this work, the driving force for formation of $b$ is an increase in $c_{a}$ above a saturation value, $c_{a, s a t}$, which is equal to the equilibrium concentration in $a\left(c_{a}{ }^{*}\right)$, for this case. This hypothesis suggests that, although phase $a$ has a welldefined equilibrium concentration, it is able to exist in a supersaturated state with a concentration of solid-state lithium greater than the equilibrium concentration (see Figure 1). Assuming that only the $a$ phase is electrochemically active, the formation of $b$ can be described by the following 
two-step process, whereby lithium is first inserted into $a$ and then the host material rearranges into the equilibrium phases:

$$
\begin{gathered}
\mathrm{Li}_{\mathrm{a}} \Gamma_{\mathrm{a}}+\mathrm{xLi}^{+}+\mathrm{xe}^{-} \stackrel{\text { lithiation }}{\longrightarrow} \mathrm{Li}_{\mathrm{a}+\mathrm{x}} \Gamma_{\mathrm{a}} \\
\mathrm{Li}_{\mathrm{a}+\mathrm{x}} \Gamma_{\mathrm{a}} \stackrel{\text { phase change }}{\longrightarrow} \mathrm{yLi}_{\mathrm{a}} \Gamma_{\mathrm{a}}+(1-\mathrm{y}) \mathrm{Li}_{\mathrm{b}} \Gamma_{\mathrm{b}} \text {, where } y=\frac{a+x-b}{a-b}
\end{gathered}
$$

During lithiation of a material with non-instantaneous formation of phase $b$, the voltage does not remain constant between $c_{a}{ }^{*}$ and $c_{b}{ }^{*}$. The voltage depends on the degree of supersaturation of phase $a$, which can continuously change during lithiation and depends on the relative rates of the two steps.

(Insert Figure 1 here)

In this work, the kinetic description for the formation of $b$ from $a$ in Eq. 3 is given as follows:

$$
\begin{gathered}
\frac{\partial \theta_{b}}{\partial t}=k_{b}\left(c_{a}-c_{a, s a t}\right) \theta_{b}^{2 / 3}\left(1-\theta_{b}\right) \\
k_{b}=k_{b, 1}\left(1+k_{b, 2} c_{a}\right)
\end{gathered}
$$

where $\theta$ corresponds to the volume fraction of a given structure. The $2 / 3$ dependence on $\theta_{b}$ results from the assumptions that new structures of phase $b$ nucleate as spheres and grow in three dimensions [44]. The term $\left(1-\theta_{b}\right)$ causes a reduction in the rate of formation as the volume fraction of $a$ approaches zero [45]. The rate constant for formation $k_{b}$ is assumed to depend linearly on $c_{a}$. A more detailed description of the formulation can be found in [48].

(Insert Figure 2 here)

Figure 2 provides a pictorial representation of the process described by Eq. 4 for a slow, moderate, and fast rate of $\theta_{b}$ formation. The pictorial representation was developed assuming that 
a single crystal of host material comprised of only phase $a$ and at an initial solid-state lithium concentration, $c_{a, 0}$, is lithiated uniformly at a constant reaction rate. At the start of lithiation $\left(c_{a}<\right.$ $c_{a, \text { sat }}$ ), only $\theta_{a}$ is present, and $c_{a}$ increases linearly with time as a result of the constant reaction rate. As the concentration in $a$ exceeds the critical saturation concentration $\left(c_{a, s a t}\right)$, phase $b$ starts to form, which decreases the volume fraction of $a\left(\theta_{a}\right)$ in the crystal. In addition, the formation of phase $b$ impacts $c_{a}$ due to the rearrangement of solid-state lithium within the particle. The value of $c_{a}$ can be determined through a mass balance on the total amount of solid-state lithium in the particle, as follows:

$$
\frac{\partial\left(\theta_{a} c_{a}\right)}{\partial t}+\frac{\partial\left(\theta_{b} c_{b}\right)}{\partial t}=\frac{3 i_{r x n}}{r_{x} n F}
$$

where $r_{x}$ is the radius of the crystal, and it is assumed only the $a$-phase is electrochemically active. Assuming a negligible difference between the size of the unit cells of phases $a$ and $b$ and a constant value of $c_{b}=c_{b}{ }^{*}$, which corresponds to the concentration at equilibrium, Eq. 5 can be simplified to:

$$
\left(1-\theta_{b}\right) \frac{\partial c_{a}}{\partial t}=\left(c_{a}-c_{b}^{*}\right) \frac{\partial \theta_{b}}{\partial t}+\frac{3 i_{r x n}}{r_{x} n F}
$$

The values of $c_{a}$ during a slow, moderate, and fast rate of $\theta_{b}$ formation are also shown in Figure 2a. If no $\theta_{b}$ is formed, $c_{a}$ increases linearly with time. If $\theta_{b}$ is formed, the rate of change of $c_{a}$ decreases because $c_{a}<c_{b}{ }^{*}$, which indicates that the formation of $\theta_{b}$ corresponds to a "repackaging" of the solid-state lithium in the particle into a more concentrated structure. Because only the $a$-phase is assumed to be electrochemically active, the variations in $c_{a}$ for the different rates of formation result in variations in the voltage profile observed during discharge. Therefore, accurate modeling of this process requires determination of $c_{a, s a t}, c_{b}{ }^{*}$, a description of the supersaturation potential for $c_{a}$, and the rate constants $k_{b, 1}$ and $k_{b, 2}$. In the remainder of this 
work, the approach described herein is adapted to simulate the phase changes occurring within magnetite electrodes during lithiation and voltage recovery experiments. Whenever possible, insights from the experimental literature are used to refine the underlining assumptions of the model.

\section{Experimental Results and Discussion}

Adapting the phase change model for magnetite first requires determination of the phases from experimental results. Figure 3 shows the results of the voltage recovery experiments, whereby electrodes comprised of 6,8 , and $32 \mathrm{~nm} \mathrm{Fe}_{3} \mathrm{O}_{4}$ crystals were lithiated to a set concentration of lithium $\left(x\right.$ in $\mathrm{Li}_{x} \mathrm{Fe}_{3} \mathrm{O}_{4}$ ) and then allowed to rest under open circuit conditions for up to 30 days. The figure plots the maximum voltage for each electrode during the 30-day rest period. According to this plot, there are two plateaus in the equilibrium potential of $\mathrm{Fe}_{3} \mathrm{O}_{4}$. The first plateau starts at $x \sim 1$, and the second starts at $x \sim 6$. The existence of two plateaus indicates that there are two regions where $\mathrm{Fe}_{3} \mathrm{O}_{4}$ undergoes an electrochemical reaction involving two solid phases. This suggests that $\mathrm{Fe}_{3} \mathrm{O}_{4}$ can exist in three unique arrangements, referred to herein as $\alpha, \beta$, and $\gamma$.

(Insert Figure 3 here)

The first voltage plateau at $x=1$ corresponds to an equilibrium between the $\alpha$ - and $\beta$ phases. According to the schematic in Figure 1, the existence of the plateau from $x=1$ to $x=3$ suggests that, at equilibrium, the $\alpha$ phase has a solid state lithium concentration of $x=1$ ( $\alpha$ $\mathrm{LiFe}_{3} \mathrm{O}_{4}$ ) and the $\beta$ phase has a concentration of $x=3$. However, this result is only valid under the assumption that the voltage recovery experiments have reached equilibrium potentials after 30 days. For experiments lithiated to $x<3.0$, the electrodes are close to equilibrium after 30 days 
and the voltage in Figure 3 roughly corresponds to the equilibrium potential [41, 42]. For experiments lithiated to $x>3.0$, the voltage of the electrodes is still changing significantly at 30 days. For instance, the inset in Figure 3 shows that the voltages of electrodes discharged to 4 moles of $\mathrm{Li}^{+}$per mole of $\mathrm{Fe}_{3} \mathrm{O}_{4}$ are still rapidly changing at 30 days. In addition, structural characterization suggests the existence of a rock-salt phase at a concentration of $x=4$, which has a structure resembling $\mathrm{Li}_{2} \mathrm{O}$ and $\mathrm{FeO}$ closely packed on an O-anion framework [21]. Therefore, in this work, the $\beta$ phase is assumed to have an equilibrium structure of the form $\beta-\mathrm{Li}_{4} \mathrm{Fe}_{3} \mathrm{O}_{4}$, and the first voltage plateau is assumed to extend to $x=4$. Based on this assumption, the reaction for the instantaneous formation of the $\beta$ phase is given as follows:

$$
\underbrace{\mathrm{LiFe}_{3} \mathrm{O}_{4}}_{\alpha}+3 \mathrm{Li}^{+}+3 \mathrm{e}^{-} \rightarrow \underbrace{\mathrm{Li}_{4} \mathrm{Fe}_{3} \mathrm{O}_{4}}_{\beta}
$$

For the second plateau, it extends out to $x=8$ and is believed to be associated with the conversion reaction that forms $\mathrm{Li}_{2} \mathrm{O}$ and metallic $\mathrm{Fe}$ [21]. In this work, these conversion products are represented as the $\gamma$ phase, which is assumed to have a solid-state lithium concentration of $x$ $=8$ lithium per $\mathrm{Fe}_{3} \mathrm{O}_{4}$. Note the term "phase" is used to describe these products based on the definition of a phase presented in Section 3: a unique arrangement of the host atoms containing a set concentration of solid-state lithium at equilibrium. $\gamma$ may also be defined as the product of a conversion reaction with two phases $\left(\mathrm{Li}_{2} \mathrm{O}\right.$ and metallic $\left.\mathrm{Fe}\right)$; however, this is not the definition of phase used herein. The instantaneous formation of $\gamma$ can be expressed by the following equation:

$$
\mathrm{Li}_{\mathrm{y}} \mathrm{Fe}_{3} \mathrm{O}_{4}+(8-\mathrm{y}) \mathrm{Li}^{+}+(8-\mathrm{y}) \mathrm{e}^{-} \rightarrow \underbrace{4 \mathrm{Li}_{2} \mathrm{O}+3 \mathrm{Fe}}_{\gamma}
$$

where the solid-state concentration at the onset of the plateau is defined by the variable $y$. The solid-state concentration at the onset is unknown because the voltage recovery experiments are 

experimental results (see Section 5.2.2).

Evidence of these phases during lithiation of electrodes containing 8 and $32 \mathrm{~nm} \mathrm{Fe}_{3} \mathrm{O}_{4}$ crystals at a C/200 rate is shown in Figure 4. The degree of lithiation (i.e., lithiated capacity) is defined as the average moles of lithium inserted into one mole of $\mathrm{Fe}_{3} \mathrm{O}_{4}$ electrode material. For both curves, the plateaus at $\sim 1.5 \mathrm{~V}$ and $\sim 1.2 \mathrm{~V}$ correspond to $\beta$ and $\gamma$ formation, respectively. Note that these "plateaus" do not maintain a constant voltage during lithiation, which suggests that the formations of $\beta$ and $\gamma$ are non-instantaneous. The third plateau at $\sim 0.8 \mathrm{~V}$ can be attributed to continual lithiation accompanied by electrolyte reduction [49]. To avoid uncertainty associated with the electrolyte reduction, the analysis of phase change is restricted to lithiation above $1.0 \mathrm{~V}$. Differences in the degree of lithiation at which these three plateaus are observed can be attributed to lithium transport resistances that result in higher local solid-state concentrations within the electrodes containing $32 \mathrm{~nm}$ crystals [24]. For instance, the inset in the figure plots the experimental voltage versus the maximum solid-state lithium concentration predicted by the model given in Section 5.2. The data was obtained by cross-referencing the experimental voltage at a given degree of lithiation to the predicted maximum solid-state concentration at that same degree of lithiation. The results indicate that the voltage plateaus for the 8 and $32 \mathrm{~nm}$ crystals correspond to the same maximum solid-state concentration in the electrode.

(Insert Figure 4 here)

\section{Modeling}

The phase changes in magnetite are modeled using a two-step approach. First, the model for the formation of $\beta-\mathrm{Li}_{4} \mathrm{Fe}_{3} \mathrm{O}_{4}$ from $\alpha-\mathrm{Li}_{\mathrm{x}} \mathrm{Fe}_{3} \mathrm{O}_{4}$ is proposed and validated against lithiation and 
voltage recovery experiments at low levels of lithiation $\left(x_{\text {avg }}<2.5\right.$ for $x$ in $\left.\mathrm{Li}_{\mathrm{x}} \mathrm{Fe}_{3} \mathrm{O}_{4}\right)$ and for small crystals $(6$ and $8 \mathrm{~nm})$. These experimental conditions were selected to avoid $\gamma$ phase formation. Second, insight from this $\beta$-formation model is used to justify the development of a unique model which describes the phase formation of the $\gamma$ phase directly from $\alpha-\mathrm{Li}_{\mathrm{x}} \mathrm{Fe}_{3} \mathrm{O}_{4}$ during lithiation. The $\gamma$-formation model is then used to provide insight into the suggested behavior of magnetite at increased levels of lithiation in small $(6 \mathrm{~nm})$ and large $(32 \mathrm{~nm})$ crystals.

\subsection{Phase change from $\alpha-\mathrm{Li}_{x} \mathrm{Fe}_{3} \mathrm{O}_{4}$ to $\beta$ - $\mathrm{Li}_{4} \mathrm{Fe}_{3} \mathrm{O}_{4}$}

\subsubsection{Formulation with $\beta-\mathrm{Li}_{4} \mathrm{Fe}_{3} \mathrm{O}_{4}$ Phase}

The phase change from $\alpha-\mathrm{Li}_{x} \mathrm{Fe}_{3} \mathrm{O}_{4}$ to $\beta-\mathrm{Li}_{4} \mathrm{Fe}_{3} \mathrm{O}_{4}$ is simulated by incorporating the kinetic description in Eq. 1 into a previously developed model [41-43]. The previously developed model, which does not include phase change, simulates the electrochemical performance of a $\mathrm{Fe}_{3} \mathrm{O}_{4}$ electrode by coupling the lithium transport in the agglomerate and crystal length-scales to thermodynamic and kinetic expressions. Full details of the model without phase change, including assumptions and numerical solution techniques can be found in [42]. Similar numerical techniques are used to solve the models with phase change proposed herein.

A comparison of the governing equations and boundary conditions of the models with and without phase change is provided in Tables I and II. The two formulations are identical in the agglomerate length-scale. Differences in the formulations arise in the treatment of mass transport and phase formation on the crystal length-scale. In the phase change model, the $\beta$ phase is assumed to undergo a non-instantaneous formation according to the following process:

$$
\underbrace{\mathrm{LiFe}_{3} \mathrm{O}_{4}}_{\alpha}+\mathrm{xLi}^{+}+\mathrm{xe}^{-} \rightleftharpoons \underbrace{\mathrm{Li}_{1+\mathrm{x}} \mathrm{Fe}_{3} \mathrm{O}_{4}}_{\alpha}
$$




$$
\underbrace{\mathrm{Li}_{1+x} \mathrm{Fe}_{3} \mathrm{O}_{4}}_{\alpha} \rightleftharpoons \underbrace{\mathrm{yiFe} \mathrm{O}_{3}}_{\alpha}+(1-y) \underbrace{\mathrm{Li}_{4} \mathrm{Fe}_{3} \mathrm{O}_{4}}_{\beta} \text {, where } y=1-\frac{x}{3}
$$

Equations 9 and 10 are formulated to show that phase change only occurs when $x>1$ in the $\alpha$ phase. To determine the volume fraction of the $\beta$ phase, the kinetic description in Eq. 4 can be rewritten as follows:

$$
\begin{gathered}
\frac{\partial \theta_{\beta}}{\partial t}=k_{\beta}\left(c_{\alpha}-c_{\alpha, s a t}^{\beta}\right) \theta_{\beta}^{2 / 3}\left(1-\theta_{\beta}\right) \\
k_{\beta}=k_{\beta, 1}\left(1+k_{\beta, 2} c_{\alpha}\right)
\end{gathered}
$$

where $c_{\alpha, s a t}^{\beta}$ is the saturation concentration in $\alpha$ at which $\beta$ starts to form. The volume fraction of $\alpha$ phase is calculated from a conservation of mass as follows:

$$
\theta_{\alpha}+\theta_{\beta}=1
$$

For numerical simplicity, this formulation assumes the unit cells of $\alpha$ and $\beta$ are similar, neglecting the $\sim 7.8 \%$ volume expansion of magnetite during lithiation from a spinel ( $\alpha$ phase) to rock-salt-like ( $\beta$ phase) structure [22]. Note that, physically, a slight expansion in crystal volume would increase the path length of ion diffusion, which would negatively impact the solid-state transport (assuming the mechanism of solid state transport remains unchanged by the phase formation). In this model, the relative ease (or difficulty) of solid-state transport is governed by the solid state diffusion coefficient $\left(D_{x, \text { eff }}\right.$, Eq. 13), which is fit to experimental data. Therefore, neglecting the $<10 \%$ volume expansion may have a slight impact on the absolute value of $D_{x, \text { eff }}$ (less than an order of magnitude), but it is not expected to change any conclusions predicted by the model about the relative importance of the solid-state transport within magnetite.

At present, there is a lack of experimental evidence defining the precise mechanism of lithium transport in $\alpha$ and/or $\beta$. For simplicity, it is assumed that lithium can only move through 
the $\alpha$ phase. To calculate the distribution of solid-state lithium in the crystal, a mass balance on the total lithium in the $\alpha$ phase is conducted, yielding the following:

$$
\left(1-\theta_{\beta}\right) \frac{\partial c_{\alpha}}{\partial t}=\nabla \cdot\left(D_{x, e f f} \nabla c_{\alpha}\right)+\left(c_{\alpha}-c_{\beta}\right) \frac{\partial \theta_{\beta}}{\partial t}
$$

This equation is formulated based on the same assumption used to develop Eq. 6 - i.e., that the lithium concentration in the newly formed $\beta$ phase is constant. This assumption is adopted due to a lack of contradictory evidence in the literature. The effective diffusion coefficient, $D_{x, e f f}$, in Eq. 13 is defined as:

$$
D_{x, e f f}=\theta_{\alpha} D_{x, \alpha}
$$

The total concentration of solid-state lithium, $c_{x}$, at a given location in a crystal can be calculated from:

$$
c_{x}=c_{\alpha} \theta_{\alpha}+c_{\beta} \theta_{\beta}
$$

In addition, this formulation assumes only the $\alpha$ phase is electrochemically active, which is consistent with the previous assumption of a constant lithium concentration in the $\beta$ phase. To account for this assumption, slight variations were made to the kinetic expressions and the boundary conditions at the crystal surface, which are provided in Tables I and II.

\section{(Insert Tables I and II here)}

The last difference between the models with and without phase change is the expression used to model the open circuit potential of the system. According to the schematic in Figure 1, the open circuit potential during discharge of a system with phase change depends on the degree of supersaturation of the $\alpha$ phase. Therefore, an expression is needed for the open circuit potential as a function of the concentration of solid-state lithium in the $\alpha$ phase, $c_{\alpha}$. This expression is obtained by fitting a thermodynamic equation to a set of experimental data obtained 
from the voltage recovery experiments. The procedure for the fitting is provided in Appendix A. The experimental data are obtained by exploiting the fact that the voltage recovery curves (see inset in Figure 3 for example) have two characteristic regions. During the first $~ 200$ hours, there is a voltage recovery that can be attributed to the relaxation of concentration profiles in the agglomerate and crystal length-scales [42]. Afterwards, there is a slower, seemingly linear recovery at long times that can be attributed to phase change. Assuming that the concentration distributions relax more quickly than the phase transformation, at the start of the linear region of the recovery curve, $\mathrm{Fe}_{3} \mathrm{O}_{4}$ mostly exists in the $\alpha$ phase. Therefore, at this point, $c_{\alpha} \sim c_{x}$. The open circuit potential in the $\alpha$ phase at each degree of lithiation can then be approximated using the voltage at this point.

\subsubsection{Model Parameterization}

In our previous work, the mass transport diffusion coefficients in the model without phase change $\left(D_{\text {agg }}\right.$ and $\left.D_{x}\right)$ were determined by fitting the simulated results to experimentally observed voltage relaxation times (see Figure 3 and related discussion in [42]). A similar approach was used to fit $D_{a g g}, D_{x, \alpha}, k_{\beta, 1}$, and $k_{\beta, 2}$ to the phase change model. However, in addition to the relaxation times, the voltage transients during recovery were used to further refine the values of the model parameters. The results of the fitting procedure are shown in Figures 5 and 6. Detailed discussion of both figures can be found in Section 5.1.3. The parameters used to model the phase change and mass transport are provided in Table III along with the mass transport parameters used in the model without phase change, for comparison [42]. Values for all other parameters can be found in [41]. $c_{\alpha, \text { sat }}^{\beta}, c_{\beta}$, and $c_{\alpha, \max }$ in Table III correspond to $x=1, x=4$, and $x$ $=8$ for $x$ in $\mathrm{Li}_{\mathrm{x}} \mathrm{Fe}_{3} \mathrm{O}_{4}$, respectively (see discussion of experimental results in Section 4). The value of $c_{\alpha, \text { max }}$ assumes that the $\alpha-\mathrm{Li}_{\mathrm{x}} \mathrm{Fe}_{3} \mathrm{O}_{4}$ phase can accept the theoretical maximum of 8 moles 
of lithium per mole of $\mathrm{Fe}_{3} \mathrm{O}_{4}$, which is not unlikely due to the existence of 64 open tetrahedral sites per unit cell of $\mathrm{Fe}_{3} \mathrm{O}_{4}$ [50]. Note the good agreement between the mass transport diffusion coefficients for both models. This agreement indicates that the addition of $\beta$ formation does not change earlier conclusions that a large portion of the voltage recovery results from the relaxation of concentration distributions in the agglomerate and crystal length scales [42]. (Insert Table III here)

\subsubsection{Validation with Voltage Recovery Experiments}

Figure 5 compares experimental data for voltage recovery experiments of electrodes comprised of $6 \mathrm{~nm}$ crystals to results for simulations with and without phase change. All simulations were conducted using the model formulation described herein. Simulations without phase formation were conducted by setting the rate constant $k_{\beta, 1}$ equal to zero, which reduces the model to the formulation described in [42]. Comparisons are shown for electrodes that were lithiated to an average concentration of $x=2.0$ and 2.5 in $\mathrm{Li}_{x} \mathrm{Fe}_{3} \mathrm{O}_{4}$. At both degrees of lithiation, simulations with phase change show better agreement with experimental data. Both simulations (with and without phase change) capture the initial behavior during the first $~ 200$ hours of the voltage recovery, which is attributed to the relaxation of concentration distributions within the agglomerate and crystal length-scales. However, only the model with phase change is able to capture the gradual rise in voltage at later times, which is attributed to the rearrangement of the supersaturated $\alpha-\mathrm{Li}_{\mathrm{x}} \mathrm{Fe}_{3} \mathrm{O}_{4}$ phase into the lower energy, equilibrium phases of $\alpha-\mathrm{LiFe}_{3} \mathrm{O}_{4}$ and $\beta$ $\mathrm{Li}_{4} \mathrm{Fe}_{3} \mathrm{O}_{4}$. Similar results were obtained for electrodes comprised of $8 \mathrm{~nm}$ crystals using the same model parameters (results no shown). The 6 and $8 \mathrm{~nm}$ crystals behaved similarly because, under current operating conditions, the slight increase in crystal diameter from 6 to $8 \mathrm{~nm}$ has a negligible impact on the solid-state transport resistances [43]. An analysis of the voltage 
recovery behavior of the electrodes comprised of $32 \mathrm{~nm} \mathrm{Fe}{ }_{3} \mathrm{O}_{4}$ was not conducted due to the early onset of $\gamma-\left(4 \mathrm{Li}_{2} \mathrm{O}+3 \mathrm{Fe}\right)$ phase formation during the lithiation process, which made it difficult to pinpoint the $\alpha$ to $\beta$ phase change.

\section{(Insert Figure 5 here)}

In addition to the examples at $x=2.0$ and 2.5 in Figure 5, Figures 6 and 7 demonstrate how the model with $\beta$ - $\mathrm{Li}_{4} \mathrm{Fe}_{3} \mathrm{O}_{4}$ phase formation improves agreement with the voltage recovery experiments from $x=0.5$ to 3.0. Figures 6 and 7 compare experimental data to simulated results for two parameters used to describe the voltage recovery: the rise time and the maximum change in voltage. The rise time is defined as the time it takes the voltage to reach $90 \%$ of its maximum value during recovery. Qualitatively similar results were observed for all definitions of the rise time between $85 \%$ and $95 \%$ of the maximum voltage. In Figure 6, simulations with and without phase change show good agreement at low degrees of lithiation $(x<2.0)$ where the amount of $\beta$ formation is expected to be low because the level of supersaturation in the $\alpha$ phase is low. At higher degrees of lithiation, where the level of supersaturation in the $\alpha$ phase is high, only the simulations with $\beta$ formation are able to capture the experimental trends in rise time. Similarly, for the maximum change in voltage during recovery (Figure 7), both simulations show good agreement at low degrees of lithiation, but only the model with phase change is able to capture the performance at higher degrees of lithiation. For instance, the simulations without phase change under predict the voltage change for all recoveries where $x>1.5$.

\section{(Insert Figures 6 and 7 here)}

\subsubsection{Distributions during Voltage Recovery}

This section provides a more detailed description of the voltage recovery process according to the model by analyzing the predicted distributions of solid-state lithium $\left(c_{x}, c_{\alpha}\right)$ and 
volume fraction of $\alpha-\mathrm{Li}_{x} \mathrm{Fe}_{3} \mathrm{O}_{4}\left(\theta_{\alpha}\right)$ within the agglomerate. These distributions are shown in Figure 8 for the simulation of an agglomerate comprised of $6 \mathrm{~nm}$ crystals that was lithiated to an average concentration of $x=2.5$ in $\mathrm{Li}_{x} \mathrm{Fe}_{3} \mathrm{O}_{4}$. The times correspond to the start of the recovery process. All of the variables $\left(c_{x}, c_{\alpha}\right.$, and $\left.\theta_{\alpha}\right)$ correspond to the average value within a crystal at a given location in the agglomerate. $r$ and $r_{a g g}$ refer to the distance from the center of the agglomerate and the agglomerate radius, respectively. Figure 8a shows the distribution of the volume fraction of $\alpha$ phase. The simulations suggest that, at the start of the recovery, $\mathrm{Fe}_{3} \mathrm{O}_{4}$ is almost entirely in the $\alpha$ phase even though the concentration of solid-state lithium (Figure $8 b$ ) is well above the saturation value $(x=1)$. This occurs because of the slow kinetics of $\beta$ phase formation, which produced $<1 \%$ of $\beta$ phase during the 63-hour lithiation process. During the first 90 hours of the recovery, the $\alpha$ phase starts to transform into $\beta$ phase near the outside of the agglomerate (Fig. 8a) while the solid-state concentration in the $\alpha$ phase begins to redistribute towards a uniform concentration (Fig. 8b). The redistribution in the $\alpha$ phase is controlled by mass transport of lithium ions through the pores of the agglomerate [42]. The majority of the $\beta$ phase is formed near the edge of the agglomerate because, initially, the $\alpha$ phase is at a higher supersaturated concentration at that location. The higher concentration arises because mass transport resistances restrict the lithiation reaction towards the outside of the agglomerate during discharge.

According to the model, between 180 and 360 hours, the concentration in the $\alpha$ phase completely relaxes to a uniform value. This corresponds to the end of the initial region of the voltage recovery described by the inset in Figure 3. After this time, the concentration continues to change, which is caused by the formation of $\beta$ phase. The concentration decreases as $\beta$ phase is formed because the solid-state concentration in the $\beta$ phase is higher $(x=4)$ than the 
concentration in the $\alpha$ phase (see Eq. 13). This period corresponds to the slow, linear portion of the recovery (see Figure 5b). At the end of the 30-day recovery (720 hours), the model predicts $43 \%$ of $\mathrm{Fe}_{3} \mathrm{O}_{4}$ is in the $\beta$ phase. Note that, according to the model, because of the uneven distribution of $\beta$ within the agglomerate, at the end of recovery, concentration of total solid-state lithium $\left(c_{x}\right)$ is higher at the edge of the agglomerate (see inset in Figure 8b).

\section{(Insert Figure 8 here)}

\subsection{Conversion from $\alpha-\mathrm{Li}_{x} \mathrm{Fe}_{3} \mathrm{O}_{4}$ to $\gamma-\left(4 \mathrm{Li}_{2} \mathrm{O}+3 \mathrm{Fe}\right)$}

According to the previous section, the rate of $\beta$ formation is slow with almost no $\beta$ forming during the lithiation of the electrode. Due to the absence of $\beta$ phase, it is unlikely that the $\gamma$ "phase" (which is comprised of $\mathrm{Li}_{2} \mathrm{O}+\mathrm{Fe}$ metal) forms from $\beta$ - $\mathrm{Li}_{4} \mathrm{Fe}_{3} \mathrm{O}_{4}$. Instead, we hypothesize that the $\gamma$ phase forms directly from $\alpha-\mathrm{Li}_{x} \mathrm{Fe}_{3} \mathrm{O}_{4}$. Therefore, in order to explain the behavior of $\mathrm{Fe}_{3} \mathrm{O}_{4}$ electrodes with small $(6 \mathrm{~nm})$ and large $(32 \mathrm{~nm})$ crystals during lithiation to 1.0 $\mathrm{V}$, a version of the model was formulated, which incorporated the phase change from of $\alpha$ to $\gamma$ (without any $\beta$ phase).

\subsubsection{Formulation with $\gamma-\left(4 \mathrm{Li}_{2} \mathrm{O}+3 \mathrm{Fe}\right)$}

In this formulation, the $\gamma-\left(4 \mathrm{Li}_{2} \mathrm{O}+3 \mathrm{Fe}\right)$ is assumed to undergo a non-instantaneous formation from the $\alpha$ phase according to the following process:

$$
\begin{gathered}
\underbrace{\mathrm{Li}_{4} \mathrm{Fe}_{3} \mathrm{O}_{4}}_{\alpha}+\mathrm{xLi}^{+}+\mathrm{xe}^{-} \rightleftharpoons \underbrace{\mathrm{Li}_{4+\mathrm{x}} \mathrm{Fe}_{3} \mathrm{O}_{4}}_{\alpha} \\
\underbrace{\mathrm{Li}_{4+x} \mathrm{Fe}_{3} O_{4}}_{\alpha} \rightleftharpoons \underbrace{\mathrm{yi_{4 } \mathrm { Fe } _ { 3 } O _ { 4 }}}_{\alpha}+(1-y) \underbrace{\left(4 \mathrm{Li}_{2} \mathrm{O}+3 \mathrm{Fe}\right)}_{\gamma}, \text { where } y=1-\frac{x}{4}
\end{gathered}
$$

Equations 16 and 17 are formulated to show that $\gamma$ formation only occurs when $x>4$ in the $\alpha$ phase. This value of $x$ was determined by fitting the model to experimental data (see Figure 10 
and related discussion). The governing equations and boundary conditions for the model with $\gamma$ are almost identical to the equations for $\beta$ phase formation (see Tables I and II). Changes are only made to the values of the constants used to solve for the mass transport in the crystal and the phase change. These equations are rewritten for the model with $\gamma$ formation as follows:

$$
\begin{gathered}
\left(1-\theta_{\gamma}\right) \frac{\partial c_{\alpha}}{\partial t}=\nabla \cdot\left(D_{x, e f f} \nabla c_{\alpha}\right)+\left(c_{\alpha}-c_{\gamma}\right) \frac{\partial \theta_{\gamma}}{\partial t} \\
c_{x}=c_{\alpha} \theta_{\alpha}+c_{\gamma} \theta_{\gamma} \\
\frac{\partial \theta_{\gamma}}{\partial t}=k_{\gamma}\left(c_{\alpha}-c_{\alpha, s a t}^{\gamma}\right) \theta_{\gamma}^{2 / 3}\left(1-\theta_{\gamma}\right)
\end{gathered}
$$

The $\gamma$-phase model is formulated assuming only the $\alpha$ phase is electrochemically active since $\gamma$ represents the theoretical limit of lithiation into magnetite. In addition, to the best of our knowledge, there is no general consensus on the volume change of magnetite upon electrochemical lithiation to the $\gamma$ phase $\left(8 \mathrm{Li}\right.$ ions per $\mathrm{Fe}_{3} \mathrm{O}_{4}$ ). However, recent work has suggested that the structure of the $\gamma$ phase resembles the spinel-structure of the rock-salt-like $\beta$ phase with the $\mathrm{O}$-anions in $\mathrm{Li}_{2} \mathrm{O}$ retaining a ccp framework and $\mathrm{Fe}$ staying in the octahedral sites [21]. Therefore, we hypothesize the volume expansion from $\alpha$ to $\gamma$ is similar to that observed from $\alpha$ to $\beta$. Once again, we assume the volume expansion has a negligible impact on the electrochemical performance and neglect it in the formulation (see discussion after Eq. 12).

The major difference between the models is the definition of the effective diffusion coefficient. Recent investigations using in situ TEM have revealed that, even after a shell of $\gamma$ "phase" $\left(\mathrm{Li}_{2} \mathrm{O}+\mathrm{Fe}\right.$ metal) forms around a nanocrystal of $\mathrm{Fe}_{3} \mathrm{O}_{4}$, the inside of the crystal continues to lithiate [23]. This suggests that lithium ions are able to diffuse through $\gamma-\left(4 \mathrm{Li}_{2} \mathrm{O}+3\right.$ $\mathrm{Fe}$ ). One possible mechanism of diffusion is between the grain boundaries of the nanosized 
structures of $\mathrm{Li}_{2} \mathrm{O}$ and $\mathrm{Fe}$ metal [51]. To account for this additional pathway for lithium transport, the effective diffusion coefficient is defined as:

$$
\begin{gathered}
D_{x, \text { eff }}=\theta_{\alpha} D_{x, \alpha}\left(1-\frac{c_{\alpha}}{c_{\alpha, \max }}\right)+\theta_{\gamma} D_{x, \gamma} \\
\text { where, } \theta_{\alpha}+\theta_{\gamma}=1
\end{gathered}
$$

Equation 21 was developed assuming there are two pathways which solid-state lithium $\left(c_{\alpha}\right)$ can transport through the crystal: $i$ ) diffusion through the $\alpha$ phase and ii) diffusion through the nanograins of the $\gamma$ structure. The equation was formulated using an equivalent circuit model with both pathways existing in parallel. In addition, the effective diffusion coefficient $\left(D_{x, e f f}\right)$ includes a relation of $\left(1-c_{\alpha} / c_{\alpha, \max }\right)$ within the $\alpha$ phase. This relation has been previously used in battery simulations to account for a decrease in the diffusivity at higher concentrations of solidstate lithium, which results from a decline in the number of lattice sites available for diffusion $[32,52]$. For simplicity, this relation was not included in the previous phase-change model ( $\alpha$ to $\beta$ ) because the analysis was restricted to small crystals $(6$ and $8 \mathrm{~nm})$ where solid-state transport resistances are negligible [42].

Figure 9 shows how the inclusion of the $\left(1-c_{\alpha} / c_{\alpha, \max }\right)$ relation in the definition of the effective diffusion coefficient (Eq. 21) improves the simulated results. The figure compares simulations to experimental data for lithiation of $32 \mathrm{~nm} \mathrm{Fe} \mathrm{O}_{4}$ at $\mathrm{C} / 200$. Simulated results for small $(6 \mathrm{~nm})$ crystals were not impacted by this relation and, therefore, are not included in the figure. Both simulations were run using the $\gamma$-model with the same parameters, constants, and governing equations (see section 5.2.2 for discussion of parameters). The only difference between the simulations is whether or not the $\left(1-c_{\alpha} / c_{\alpha, \max }\right)$ relation is included in the definition 
of the effective diffusion coefficient. According to Figure 9, the simulation with the (1$\left.c_{\alpha} / c_{a, \max }\right)$ relation shows much better agreement with experimental data, especially during lithiation up to $x=1$. Without this term, the model under predicts the decrease in voltage at the onset of lithiation. This suggests that the initial decrease in voltage before the phase-change plateau is accelerated by an increase in the mass transport resistances of solid-state lithium within the crystal. Note that slight deviations still exist between the experiments and the model with the $\left(1-c_{\alpha} / c_{\alpha, \max }\right)$ relation. These deviations likely result from an oversimplification of the relationship between solid-state concentration and diffusivity. For instance, studies have shown that the solid-state diffusion coefficient of lithium in graphite can be expressed by a series of exponential relations, which depend on the solid-state lithium concentration [53].

\section{(Insert Figure 9 here)}

\subsubsection{Model Parameterization and Analysis}

The mass transport and phase-change parameters for the simulations with $\gamma$ formation are provided in Table IV. The values of all other parameters and constants are unchanged from the previously developed model $[41,42]$. The diffusion coefficient in $\gamma\left(D_{x, y}\right)$ was selected to approximate "infinitely" fast diffusion when compared to diffusion in the $\alpha$ phase. The supersaturation value at which $\gamma$ forms from the $\alpha$ phase $\left(c_{\alpha, s a t}^{\gamma}\right)$ and the rate constant for formation $\left(k_{\gamma}\right)$ were determined by fitting simulations to experimental data for lithiation of 6 and $32 \mathrm{~nm} \mathrm{Fe}{ }_{3} \mathrm{O}_{4}$ at $\mathrm{C} / 200$. The parameterization was conducted by assuming $c_{\alpha, s a t}^{\gamma}$, which describes the thermodynamic driving force for phase formation, is a material property that does not depend on the size of the nano-crystal. In turn, it was assumed $k_{\gamma}$, which describes the kinetic rate of phase formation, is not a material property that does depend on the size of the crystal. 
The results of fitting $c_{\alpha, s a t}^{\gamma}$ are shown in Figure 10 for the electrodes containing $32 \mathrm{~nm}$ crystals. Best agreement was obtained for a solid-state lithium concentration of $x=4$, for $x$ in $\mathrm{Li}_{\mathrm{x}} \mathrm{Fe}_{3} \mathrm{O}_{4}$. For fitting $k_{\gamma}$, comparisons of simulations to experiments during the lithiation of 6 and $32 \mathrm{~nm} \mathrm{Fe} \mathrm{O}_{4}$ at $\mathrm{C} / 200$ is shown in Figure 11. Three simulations were conducted for each crystal size: $i)$ no $\gamma$ formation, $i i) \gamma$ formation with the rate constant fit to the $6 \mathrm{~nm}$ experiments $\left(k_{\gamma}=0.8\right.$ $\left.\times 10^{-3} \mathrm{~cm}^{3} \mathrm{~mol}^{-1} \mathrm{~s}^{-1}\right)$, and iii) $\gamma$ formation with the rate constant fit to the $32 \mathrm{~nm}$ experiments $\left(k_{\gamma}=\right.$ $\left.2.5 \times 10^{-3} \mathrm{~cm}^{3} \mathrm{~mol}^{-1} \mathrm{~s}^{-1}\right)$. The results indicate that the rate constant associated with $\gamma$ formation decreases as the size of the $\mathrm{Fe}_{3} \mathrm{O}_{4}$ crystal decreases. Therefore, the rate of $\gamma$ formation is predicted to decrease as the size of the crystal decreases. This trend is in agreement with other nanoscale lithiation materials. For instance, decreasing the crystal size in the nanoscale regime of both $\mathrm{FePO}_{4}$ and $\mathrm{TiO}_{2}$ has been shown to suppress phase separation $[54,55]$. It has been suggested that phase separation is suppressed because the surface strain between the two phases becomes energetically too costly for the smaller crystals [54].

\section{(Insert Figures 10 and 11 here)}

\subsubsection{Phase Distributions during Lithiation of 6 and $32 \mathrm{~nm} \mathrm{Fe}_{3} \mathrm{O}_{4}$}

In addition to impacting the rate constant associated with formation of $\gamma$, the model suggests the size of the crystal impacts the onset of the conversion process, where the onset is measured in reference to the total number of coulombs passed into the electrode. The onset of $\gamma$ formation occurs earlier in the electrodes with larger crystals because of an increase in the solidstate transport limitations. For example, Figure 12 shows predicted profiles of the volume fraction of the $\alpha$ phase in the crystal at the edge of the agglomerate. Simulations were conducted using the best fit values for $k_{\gamma}$ (i.e., $0.8 \times 10^{-3}$ and $2.5 \times 10^{-3}$ for 6 and $32 \mathrm{~nm}$ crystals, respectively). The crystal at the edge of the agglomerate was chosen because it has the highest 
degree of lithiation in the agglomerate, which results in the maximum amount of phase change. In the figure, $r_{x}$ and $\bar{r}$ are the radius of the crystal and the distance from the center of the crystal, respectively. The $x_{\text {avg }}$ label corresponds to the degree of lithiation (i.e., lithiated capacity) and is defined as the average moles of lithium inserted into one mole of $\mathrm{Fe}_{3} \mathrm{O}_{4}$ electrode material. The profiles for the electrodes with $6 \mathrm{~nm}$ crystals (Figure 12a) indicate that the conversion from $\alpha$ to $\gamma$ starts at $x_{a v g} \sim 2.75$. Once initiated, the conversion occurs relatively uniformly within the crystal due to small mass transport limitations [42]. In contrast, the profiles for the $32 \mathrm{~nm}$ crystals (Figure 12b) indicate that conversion from $\alpha$ to $\gamma$ starts at $x_{a v g} \sim 1.0$. The early onset of $\gamma$ formation arises because of large transport limitations within the $32 \mathrm{~nm}$ crystals. The large transport limitations result in concentration gradients with higher solid-state lithium concentrations near the edge of the crystal, which drive $\gamma$ formation [42]. The presence of concentration gradients also explains the non-uniformity in the distribution of $\theta_{\alpha}$ within the crystal. For instance, when the cutoff voltage of $1.0 \mathrm{~V}$ is reached, phase formation has only occurred in the outermost $20 \%$ of the crystal radius because the innermost region was at a solidstate lithium concentration below the supersaturated concentration, $c_{\alpha, s a t}^{\gamma}$.

\section{(Insert Figure 12 here)}

Simulations of the lithiation to $1.0 \mathrm{~V}$ were also conducted using a model which incorporated phase formation from $\alpha$ to $\beta$ and $\alpha$ to $\gamma$. The model was formulated with the same kinetic descriptions of phase formation defined in Equations 11 and 20. No changes were made to the values of parameters and constants given in Tables III and IV. The objective was to test the assumption that there is negligible $\beta$ formation during lithiation, and, therefore, $\gamma$ must be directly formed from the $\alpha$ phase. The resulting simulations predict negligible formation of $\beta$ phase during the lithiation of the 6 and $32 \mathrm{~nm}$ crystals to the $1.0 \mathrm{~V}$ cutoff voltage. For instance, 
when the cutoff voltage is reached, the maximum volume fraction of $\beta$ phase (i.e., the value of $\theta_{\beta}$ at the edge of the crystal at the edge of the agglomerate) for electrodes comprised of 6 and $32 \mathrm{~nm}$ crystals is $6 \%$ and $0.4 \%$, respectively. These small fractions of $\beta$ phase produced negligible variations in the voltage profile. Therefore (and for brevity), no simulation data are shown.

\section{Conclusion}

In this work, a combined experimental and theoretical approach is used to describe the phase changes occurring within magnetite $\left(\mathrm{Fe}_{3} \mathrm{O}_{4}\right)$ during lithiation and voltage recovery. Data from voltage recovery experiments of 6,8 , and $32 \mathrm{~nm} \mathrm{Fe}{ }_{3} \mathrm{O}_{4}$ was utilized to identify the existence of three distinct materials, defined as: $\alpha-\mathrm{Li}_{x} \mathrm{Fe}_{3} \mathrm{O}_{4}, \beta-\mathrm{Li}_{4} \mathrm{Fe}_{3} \mathrm{O}_{4}$, and $\gamma-\left(4 \mathrm{Li}_{2} \mathrm{O}+3 \mathrm{Fe}\right)$. The formation of the $\beta$ and $\gamma$ materials was incorporated into a model, which accounted for mass transport in the agglomerate and crystal length scales. The kinetics of the phase formations were described by an expression derived from Avrami theory for nucleation and growth. It was concluded that the potential change observed at the start of the voltage recovery experiments is caused by the relaxation of concentration distributions in the agglomerate and crystal, while the slow, linear voltage change observed at long times is caused by a slow phase change from $\alpha$ $\mathrm{Li}_{x} \mathrm{Fe}_{3} \mathrm{O}_{4}$ to $\beta$ - $\mathrm{Li}_{4} \mathrm{Fe}_{3} \mathrm{O}_{4}$. In addition, it was concluded that negligible amounts of $\beta$ phase formed during lithiation of $\mathrm{Fe}_{3} \mathrm{O}_{4}$ to a $1.0 \mathrm{~V}$ cutoff due to the slow kinetics of phase change. Furthermore, simulations of the lithiation process indicate that the voltage plateau at $\sim 1.2 \mathrm{~V}$ can be attributed to the formation of $\gamma-\left(4 \mathrm{Li}_{2} \mathrm{O}+3 \mathrm{Fe}\right)$ from $\alpha-\mathrm{Li}_{x} \mathrm{Fe}_{3} \mathrm{O}_{4}$. These simulations also suggest that the rate of $\gamma$ formation is suppressed as the size of the nanocrystalline $\mathrm{Fe}_{3} \mathrm{O}_{4}$ is decreased, which is in agreement with previous studies on other nanocrystalline, lithium host materials. 


\section{Acknowledgements}

This work was supported as part of the Center for Mesoscale Transport Properties, an Energy Frontier Research Center supported by the U. S. Department of Energy, Office of Science, Basic Energy Sciences, under award \#DE-SC0012673. The computing was performed on the Yeti Shared HPC Cluster at Columbia University, which includes support from Empire State Development's Division of Science, Technology, and Innovation under contract number C090171.

\section{Appendix A: Open Circuit Potential for $\alpha-\mathrm{Li}_{x} \mathrm{Fe}_{3} \mathrm{O}_{4}$ Phase}

An equation for the open circuit potential of the $\alpha-\mathrm{Li}_{\mathrm{x}} \mathrm{Fe}_{3} \mathrm{O}_{4}$ phase as a function of the degree of supersaturation was obtained by fitting a thermodynamic expression derived from Karthikeyan et al. to experimental voltage recovery data [56]. The equation was derived based on the Redlich-Kister expression for the excess Gibbs free energy. It includes a Nernstian dependence on both the concentration of lithium ions in the agglomerate and the concentration of solid-state lithium in the $\alpha$ phase, with an activity correction for non-idealities in the $\alpha$ phase. It is defined as follows:

$$
U=U_{r e f}+\frac{R_{G} T}{F} \ln \left[\left(\frac{c_{a g g}}{c_{0}}\right)\left(\frac{\left(1-x_{\alpha}\right)}{x_{\alpha}}\right)\right]+\sum_{k=0}^{N} A_{k}\left[\left(2 x_{\alpha}-1\right)^{k+1}-\frac{2 x_{\alpha} k\left(1-x_{\alpha}\right)}{\left(2 x_{\alpha}-1\right)^{1-k}}\right] ; x_{\alpha}=\frac{c_{\alpha}}{c_{\alpha, \max }}
$$

The experimental data for the supersaturated $\alpha$ phase was approximated using the points on the voltage recovery curves where the recovery transitions from the initial region, where the voltage change is rapid, to the later region, where the voltage change is slow and seemingly linear (see inset in Figure 3). This point was assumed to represent the portion of the recovery experiment where the concentration distributions have completely relaxed, but there is still minimal phase formation. Under these assumptions, the degree of lithiation and voltage at this 
point correspond to the degree of supersaturation of the $\alpha$ phase and the open circuit potential at that degree of supersaturation, respectively. Further discussion on these assumptions is provided in Section 4.2.1. The point where the voltage recovery curve transitions into the linear region is determined mathematically based on the change in voltage $(\mathrm{dV} / \mathrm{dt})$ of the recovery experiments. The time at which this occurs is defined as the first point during the voltage recovery experiment where $\mathrm{dV} / \mathrm{dt}$ is less than twice $\mathrm{dV} / \mathrm{dt}$ at the end of the recovery experiments (first time when $\left.d V / d t<2(d V / d t)_{\text {end }}\right)$.

The maximum voltage during recovery and the supersaturated voltage defined using the above criteria are provided in Figure A.1. Both sets of data represent the average obtained from the experiments conducted with 6,8 , and $32 \mathrm{~nm} \mathrm{Fe}_{3} \mathrm{O}_{4}$ crystals. The error bars represent the maximum and minimum deviation from the average. Also included in the figure are the values predicted by the equation for the open circuit potential, which was determined by fitting Eq. A.1 to the data for the supersaturated $\alpha$ phase. The values of the constants in the fit are provided in Table A.1.

(Insert Figure A.1 and Table A.1 here)

\section{List of Symbols}

a specific surface area $\left(\mathrm{cm}^{2} \mathrm{~cm}^{-3}\right)$

$c_{a g g} \quad$ lithium concentration in the agglomerate $\left(\mathrm{mol} \mathrm{cm}^{-3}\right)$

$c_{\alpha, s a t}^{\beta} \quad$ concentration at which $\beta$ begins to form from $\alpha\left(\mathrm{mol} \mathrm{cm}^{-3}\right)$

$c_{\alpha, s a t}^{\gamma} \quad$ concentration at which $\gamma$ begins to form from $\alpha\left(\mathrm{mol} \mathrm{cm}^{-3}\right)$

$c_{0} \quad$ bulk concentration in the electrolyte $\left(\mathrm{mol} \mathrm{cm}^{-3}\right)$

$c_{x} \quad$ total solid-state lithium concentration $\left(\mathrm{mol} \mathrm{cm}^{-3}\right)$ 
$c_{\alpha, \max } \quad$ maximum solid-state lithium concentration in $\alpha$ phase $\left(\mathrm{mol} \mathrm{cm}{ }^{-3}\right)$

$D_{a g g} \quad$ diffusion coefficient in the agglomerate $\left(\mathrm{cm}^{2} \mathrm{~s}^{-1}\right)$

$D_{x} \quad$ diffusion coefficient in crystal $\left(\mathrm{cm}^{2} \mathrm{~s}^{-1}\right)$

$f \quad$ number fraction of agglomerates

F $\quad$ Faraday's constant $\left(96,485 \mathrm{C} \mathrm{mol}^{-1}\right)$

$i_{a p p} \quad$ applied current $\left(\mathrm{A} \mathrm{g}^{-1}\right)$

$i_{r x n} \quad$ reaction rate $\left(\mathrm{A} \mathrm{cm}^{-2}\right)$

$k_{\beta}, k_{\gamma} \quad$ rate constant for phase formation $\left(\mathrm{cm}^{-3} \mathrm{~mol}^{-1}\right.$ or $\left.\mathrm{cm}^{-3} \mathrm{~mol}^{-1} \mathrm{~s}^{-1}\right)$

$k_{r x n} \quad$ reaction rate constant $\left(\mathrm{mol}^{-1 / 2} \mathrm{~cm}^{-1 / 2} \mathrm{~s}^{-1}\right)$

$r \quad$ radial position in the agglomerate $(\mathrm{cm})$

$r_{\text {agg }} \quad$ agglomerate radius $(\mathrm{cm})$

$R_{G} \quad$ ideal gas constant $\left(8.314 \mathrm{~J} \mathrm{~mol}^{-1} \mathrm{~K}^{-1}\right)$

$t \quad$ time (s)

$T \quad$ temperature $(\mathrm{K})$

U equilibrium potential (V)

$\underline{\text { Greek }}$

$\alpha_{a}, \alpha_{c} \quad$ anodic and cathodic charge transfer coefficients

$\varepsilon \quad$ porosity

$\varphi_{1} \quad$ potential in the solid (V)

$\rho_{\mathrm{Fe}_{3} \mathrm{O}_{4}} \quad$ density of magnetite $\left(\mathrm{g} \mathrm{cm}^{-3}\right)$

$\sigma \quad$ conductivity of magnetite $\left(\mathrm{S} \mathrm{cm}^{-1}\right)$ 
$\underline{\text { Subscript }}$

agg denotes agglomerate

$\alpha \quad$ denotes alpha phase $\left(\mathrm{Li}_{\mathrm{x}} \mathrm{Fe}_{3} \mathrm{O}_{4}\right)$

$\beta \quad$ denotes beta phase $\left(\mathrm{Li}_{4} \mathrm{Fe}_{3} \mathrm{O}_{4}\right)$

$\gamma \quad$ denotes gamma phase $\left(4 \mathrm{Li}_{2} \mathrm{O}+3 \mathrm{Fe}\right)$

$x \quad$ denotes crystal

\section{References}

[1] M.S. Whittingham, History, Evolution, and Future Status of Energy Storage, Proc. IEEE, 100 (2012) 1518-1534.

[2] B.L. Ellis, K.T. Lee, L.F. Nazar, Positive Electrode Materials for Li-Ion and Li-Batteries, Chem. Mater., 22 (2010) 691-714.

[3] G.G. Amatucci, N. Pereira, Fluoride based electrode materials for advanced energy storage devices, J. Fluorine Chem., 128 (2007) 243-262.

[4] R. Malini, U. Uma, T. Sheela, M. Ganesan, N.G. Renganathan, Conversion reactions: a new pathway to realise energy in lithium-ion battery—review, Ionics, 15 (2009) 301-307.

[5] P. Poizot, S. Laruelle, S. Grugeon, L. Dupont, J.M. Tarascon, Nano-sized transition-metal oxides as negative-electrode materials for lithium-ion batteries, Nature, 407 (2000) 496-499.

[6] S. Kim, N. Pereira, N.A. Chernova, F. Omenya, P. Gao, M.S. Whittingham, G.G. Amatucci, D. Su, F. Wang, Structure Stabilization by Mixed Anions in Oxyfluoride Cathodes for HighEnergy Lithium Batteries, Acs Nano, 9 (2015) 10076-10084.

[7] L. Li, R. Jacobs, P. Gao, L. Gan, F. Wang, D. Morgan, S. Jin, Origins of Large Voltage Hysteresis in High-Energy-Density Metal Fluoride Lithium-Ion Battery Conversion Electrodes, J. Am. Chem. Soc., 138 (2016) 2838-2848.

[8] D.C. Bock, K.C. Kirshenbaum, J. Wang, W. Zhang, F. Wang, J. Wang, A.C. Marschilok, K.J. Takeuchi, E.S. Takeuchi, 2D Cross Sectional Analysis and Associated Electrochemistry of Composite Electrodes Containing Dispersed Agglomerates of Nanocrystalline Magnetite, Fe3O4, ACS Appl. Mater. Interfaces, 7 (2015) 13457-13466.

[9] A. Abraham, L.M. Housel, C.N. Lininger, D.C. Bock, J. Jou, F. Wang, A.C. West, A.C. Marschilok, K.J. Takeuchi, E.S. Takeuchi, Investigating the Complex Chemistry of Functional Energy Storage Systems: The Need for an Integrative, Multiscale (Molecular to Mesoscale) Perspective, ACS Cent. Sci., 2 (2016) 380-387.

[10] S. Mitra, P. Poizot, A. Finke, J.M. Tarascon, Growth and electrochemical characterization versus lithium of Fe3O4 electrodes made via electrodeposition, Adv. Funct. Mater., 16 (2006) 2281-2287.

[11] S.K. V. Sivakumar, C. A. Ross, Y. Shao-Horn, Electrochemical lithium insertion of into iron oxide spinel thin films and nanoparticles: changes in structure and magnetic properties, ECS Trans., 2 (2007) 1-11. 

of Highly Dispersed Fe3O4 Nanocrystals and Their Application in Lithium-Ion Batteries, Chem. Mater., 21 (2009) 1162-1166. [13] S. Komaba, T. Mikumo, N. Yabuuchi, A. Ogata, H. Yoshida, Y. Yamada, Electrochemical Insertion of $\mathrm{Li}$ and $\mathrm{Na}$ Ions into Nanocrystalline $\mathrm{Fe} 3 \mathrm{O} 4$ and alpha-Fe2O3 for Rechargeable Batteries, J. Electrochem. Soc., 157 (2010) A60-A65. [14] S.L. Zhu, A.C. Marschilok, E.S. Takeuchi, K.J. Takeuchi, Crystallite Size Control and Resulting Electrochemistry of Magnetite, Fe3O4, Electrochem. Solid-State Lett., 12 (2009) A91A94.

[15] S.L. Zhu, A.C. Marschilok, E.S. Takeuchi, G.T. Yee, G.B. Wang, K.J. Takeuchi, Nanocrystalline Magnetite: Synthetic Crystallite Size Control and Resulting Magnetic and Electrochemical Properties, J. Electrochem. Soc., 157 (2010) A1158-A1163.

[16] M.M. Thackeray, W.I.F. David, J.B. Goodenough, Structural characterization of the lithiated iron oxides LixFe3O4 and LixFe2O3 ( $<<x<2)$, Mater. Res. Bull., 17 (1982) 785-793. [17] M. Thackeray, L. De Picciotto, A. De Kock, P. Johnson, V. Nicholas, K. Adendorff, Spinel electrodes for lithium batteries - a review, J. Power Sources, 21 (1987) 1-8.

[18] J. Fontcuberta, J. Rodriguez, M. Pernet, G. Longworth, J.B. Goodenough, Structural and magnetic characterization of the lithiated iron oxide LixFe3O4, J. Appl. Phys., 59 (1986) 19181926.

[19] M.S. Islam, C.R.A. Catlow, Lithium Insertion into Fe3o4, J. Solid State Chem., 77 (1988) 180-189.

[20] T. Yamada, K. Morita, K. Kume, H. Yoshikawa, K. Awaga, The solid-state electrochemical reduction process of magnetite in Li batteries: in situ magnetic measurements toward electrochemical magnets, J. Mater. Chem. C, 2 (2014) 5183-5188. [21] W. Zhang, D.C. Bock, C.J. Pelliccione, Y. Li, L. Wu, Y. Zhu, A.C. Marschilok, E.S. Takeuchi, K.J. Takeuchi, F. Wang, Insights into Ionic Transport and Structural Changes in Magnetite during Multiple-Electron Transfer Reactions, Adv. Energy Mater., 6 (2016) 1502471. [22] M.C. Menard, K.J. Takeuchi, A.C. Marschilok, E.S. Takeuchi, Electrochemical discharge of nanocrystalline magnetite: structure analysis using X-ray diffraction and X-ray absorption spectroscopy, Phys. Chem. Chem. Phys., 15 (2013) 18539-18548. [23] K. He, S. Zhang, J. Li, X. Yu, Q. Meng, Y. Zhu, E. Hu, K. Sun, H. Yun, X.-Q. Yang, Y. Zhu, H. Gan, Y. Mo, E.A. Stach, C.B. Murray, D. Su, Visualizing non-equilibrium lithiation of spinel oxide via in situ transmission electron microscopy, Nat. Commun., 7 (2016) 11441. [24] C.J. Pelliccione, D.C. Bock, W. Zhang, K.W. Knehr, A.C. West, F. Wang, Y. Li, E.S. Takeuchi, A.C. Marschilok, K.J. Takeuchi, Size Dependent Behavior of Fe3O4 Crystals During Electrochemical (De)lithiation: An In Situ X-ray Diffraction, Ex Situ X-ray Absorption Spectroscopy, and Theoretical Study, in review, (2016). [25] H. Duan, J. Gnanaraj, J. Liang, Synthesis and rate performance of $\mathrm{Fe}_{3} \mathrm{O}_{4}$-based $\mathrm{Cu}$ nanostructured electrodes for Li ion batteries, J. Power Sources, 196 (2011) 4779-4784. [26] Q.Q. Xiong, J.P. Tu, Y. Lu, J. Chen, Y.X. Yu, Y.Q. Qiao, X.L. Wang, C.D. Gu, Synthesis of Hierarchical Hollow-Structured Single-Crystalline Magnetite (Fe3O4) Microspheres: The Highly Powerful Storage versus Lithium as an Anode for Lithium Ion Batteries, J. Phys. Chem. C, 116 (2012) 6495-6502.

[27] M.C. Menard, A.C. Marschilok, K.J. Takeuchi, E.S. Takeuchi, Variation in the iron oxidation states of magnetite nanocrystals as a function of crystallite size: The impact on electrochemical capacity, Electrochim. Acta, 94 (2013) 320-326. 

West, A.C. Marschilok, K.J. Takeuchi, E.S. Takeuchi, Dispersion of Nanocrystalline Fe3O4 within Composite Electrodes: Insights on Battery-Related Electrochemistry, ACS App. Mater. Interfaces, (2016) 11418-11430. [29] Y.H. Kwon, M.M. Huie, D. Choi, M. Chang, A.C. Marschilok, K.J. Takeuchi, E.S. Takeuchi, E. Reichmanis, Toward Uniformly Dispersed Battery Electrode Composite Materials: Characteristics and Performance, ACS App. Mater. Interfaces, 8 (2016) 3452-3463.

[30] B.C. Han, A. Van der Ven, D. Morgan, G. Ceder, Electrochemical modeling of intercalation processes with phase field models, Electrochim. Acta, 49 (2004) 4691-4699.

[31] G.K. Singh, G. Ceder, M.Z. Bazant, Intercalation dynamics in rechargeable battery materials: General theory and phase-transformation waves in LiFePO4, Electrochim. Acta, 53 (2008) 7599-7613.

[32] T.R. Ferguson, M.Z. Bazant, Nonequilibrium Thermodynamics of Porous Electrodes, J. Electrochem. Soc., 159 (2012) A1967-A1985.

[33] S. Dargaville, T.W. Farrell, The persistence of phase-separation in LiFePO4 with twodimensional $\mathrm{Li}+$ transport: The Cahn-Hilliard-reaction equation and the role of defects, Electrochim. Acta, 94 (2013) 143-158.

[34] H.C. Yu, F. Wang, G.G. Amatucci, K. Thornton, A Phase-Field Model and Simulation of Kinetically Asymmetric Ternary Conversion-Reconversion Transformation in Battery Electrodes, J. Phase Equilib. Diff., 37 (2016) 86-99.

[35] G. Chen, X. Song, T.J. Richardson, Electron Microscopy Study of the LiFePO4 to FePO4 Phase Transition, Electrochem. Solid-State Lett., 9 (2006) A295-A298.

[36] L. Laffont, C. Delacourt, P. Gibot, M.Y. Wu, P. Kooyman, C. Masquelier, J.M. Tarascon, Study of the LiFePO4/FePO4 Two-Phase System by High-Resolution Electron Energy Loss Spectroscopy, Chem. Mater., 18 (2006) 5520-5529. [37] R. Amin, P. Balaya, J. Maier, Anisotropy of Electronic and Ionic Transport in LiFePO4 Single Crystals, Electrochem. Solid-State Lett., 10 (2007) A13-A16.

[38] V.R. Subramanian, H.J. Ploehn, R.E. White, Shrinking core model for the discharge of a metal hydride electrode, J. Electrochem. Soc., 147 (2000) 2868-2873.

[39] V. Srinivasan, J. Newman, Discharge model for the lithium iron-phosphate electrode, J. Electrochem. Soc., 151 (2004) A1517-A1529.

[40] Y. Zhu, C. Wang, Galvanostatic Intermittent Titration Technique for Phase-Transformation Electrodes, J. Phys. Chem. C, 114 (2010) 2830-2841.

[41] K.W. Knehr, N.W. Brady, C.N. Lininger, C.A. Cama, D.C. Bock, Z. Lin, A.C. Marschilok, K.J. Takeuchi, E.S. Takeuchi, A.C. West, Mesoscale Transport in Magnetite Electrodes for Lithium-Ion Batteries, ECS Trans., 69 (2015) 7-19.

[42] K.W. Knehr, N.W. Brady, C.A. Cama, D.C. Bock, Z. Lin, C.N. Lininger, A.C. Marschilok, K.J. Takeuchi, E.S. Takeuchi, A.C. West, Modeling the Mesoscale Transport of LithiumMagnetite Electrodes Using Insight from Discharge and Voltage Recovery Experiments, J. Electrochem. Soc., 162 (2015) A2817-A2826.

[43] N.W. Brady, K.W. Knehr, C.A. Cama, C.N. Lininger, Z. Lin, A.C. Marschilok, K.J. Takeuchi, E.S. Takeuchi, A.C. West, Galvanostatic interruption of lithium insertion into magnetite: Evidence of surface layer formation, J. Power Sources, 321 (2016) 106-111. [44] M. Avrami, Kinetics of Phase Change. I General Theory, J. Chem. Phys., 7 (1939) 1103. [45] M. Avrami, Kinetics of Phase Change. II Transformation-Time Relations for Random Distribution of Nuclei, J. Chem. Phys., 8 (1940) 212. 
[46] M. Avrami, Granulation, Phase Change, and Microstructure Kinetics of Phase Change. III, J. Chem. Phys., 9 (1941) 177.

[47] A.L. Patterson, The Scherrer formula for x-ray particle size determination, Phys. Rev., 56 (1939) 978.

[48] N.W. Brady, Q. Zhang, K.W. Knehr, P. Liu, A.C. Marschilok, K. J. Takeuchi, E.S.

Takeuchi, A.C. West, Discharge, Relaxation, and Charge Model for the Lithium Trivanadate Electrode: Reactions, Phase Change, and Transport, J. Electrochem. Soc., 163 (2016) A2890A2898.

[49] X. Zhang, R. Kostecki, T.J. Richardson, J.K. Pugh, P.N. Ross, Electrochemical and Infrared Studies of the Reduction of Organic Carbonates, J. Electrochem. Soc., 148 (2001) A1341A1345.

[50] M.E. Fleet, The structure of magnetite: Symmetry of cubic spinels, J. Solid State Chem., 62 (1986) 75-82.

[51] M. Park, X. Zhang, M. Chung, G.B. Less, A.M. Sastry, A review of conduction phenomena in Li-ion batteries, J. Power Sources, 195 (2010) 7904-7929.

[52] E.B. Nauman, D.Q. He, Nonlinear diffusion and phase separation, Chem. Eng. Sci., 56 (2001) 1999-2018.

[53] D.R. Baker, M.W. Verbrugge, Intercalate Diffusion in Multiphase Electrode Materials and Application to Lithiated Graphite, J. Electrochem. Soc., 159 (2012) A1341-A1350.

[54] M. Wagemaker, W.J.H. Borghols, F.M. Mulder, Large Impact of Particle Size on Insertion Reactions. A Case for Anatase LixTiO2, J. Am. Chem. Soc., 129 (2007) 4323-4327.

[55] N. Meethong, H.-Y.S. Huang, W.C. Carter, Y.-M. Chiang, Size-Dependent Lithium Miscibility Gap in Nanoscale Li1 - x FePO4, Electrochem. Solid-State Lett., 10 (2007) A134A138.

[56] D.K. Karthikeyan, G. Sikha, R.E. White, Thermodynamic model development for lithium intercalation electrodes, J. Power Sources, 185 (2008) 1398-1407. 


\section{List of Tables}

Table I. Comparison of governing equations used in models with and without phase change. $r$ and $\bar{r}$ refer to units of distance in the agglomerate and crystal length-scales, respectively.

Table II. Comparison of boundary conditions used in models with and without phase change. $r$ and $\bar{r}$ refer to units of distance in the agglomerate and crystal length-scales, respectively. $r_{a g g}$ and $r_{x}$ are the radii of the agglomerate and crystals, respectively.

Table III. Parameters used in simulations with and without phase change from $\alpha$ - $\mathrm{Li}_{\mathrm{x}} \mathrm{Fe}_{3} \mathrm{O}_{4}$ to $\beta$ $\mathrm{Li}_{4} \mathrm{Fe}_{3} \mathrm{O}_{4}$.

Table IV. Parameters used in simulations with phase change from $\alpha-\mathrm{Li}_{\mathrm{x}} \mathrm{Fe}_{3} \mathrm{O}_{4}$ to $\gamma-\left(4 \mathrm{Li}_{2} \mathrm{O}+3\right.$ $\mathrm{Fe})$.

Table A.1. Parameters determined for the equation of the open circuit potential of the $\alpha$ phase derived from the Redlich-Kister expansion. 


\section{List of Figures}

Figure 1. Schematic of the equilibrium potential and supersaturation potential during phase change of a host material from phase $a$ (at a solid-state lithium concentration of $c_{a}$ ) to phase $b$ (at a solid-state lithium concentration of $c_{b}{ }^{*}$ ).

Figure 2. Generic results for a particle undergoing phase change from phase $a$ to $b$. a) Concentration of solid-state lithium in phase $a\left(c_{a}\right)$ and $\mathrm{b}$ ) volume fraction of phase $a\left(\theta_{a}\right)$ during uniform lithiation of a particle at a constant reaction rate. Diagrams show how $c_{a}$ and $\theta_{a}$ are impacted by the slow, moderate, and fast formation of phase $b$ (from $a$ ) as described in Eq. 1 .

Figure 3. Maximum voltage during recovery at open circuit for up to 30 days after lithiation to a set amount of $x$ in $\mathrm{Li}_{x} \mathrm{Fe}_{3} \mathrm{O}_{4}$. Inset: Experimental data for voltage recovery after lithiation to $x=4$ for $x$ in $\mathrm{Li}_{x} \mathrm{Fe}_{3} \mathrm{O}_{4}$. Voltage recovery data sectioned into an initial, rapid recovery attributed to the relaxation of concentration distributions on the agglomerate and crystal length-scales and a later, slow recovery attributed to the formation of the $\beta$ phase from the $\alpha$ phase.

Figure 4. Lithiation of pristine electrodes comprised of 8 and $32 \mathrm{~nm}$ crystals at a C/200 rate. Inset: Plot of experimental voltage vs. maximum solid-state concentration predicted by model during lithiation (see Section 4.3 for model details).

Figure 5. Comparison of experimental voltage recovery data to simulated results from models with and without phase change from $\alpha$ to $\beta$. Data is shown for recovery after lithiation to average concentrations of a) $x=2$ and b) $x=2.5 \mathrm{in}_{\mathrm{Li}_{x}} \mathrm{Fe}_{3} \mathrm{O}_{4}$ at a $\mathrm{C} / 200$ rate.

Figure 6. Rise time during voltage recovery, which is defined as the time required to reach $90 \%$ of the maximum voltage.

Figure 7. Maximum change in voltage during voltage recovery. 
Figure 8. Distributions of a) $\theta_{\alpha}$ and b) $c_{\alpha}$ within agglomerate during recovery of an agglomerate comprised of $6 \mathrm{~nm}$ crystals after a lithiation to an average concentration of $x=2.5$ in $\mathrm{Li}_{x} \mathrm{Fe}_{3} \mathrm{O}_{4}$. Times are reported with respect to the start of recovery. Inset in b): Distribution of the total solidstate lithium concentration in both the $\alpha$ and $\beta$ phases.

Figure 9. Comparison of experimental data to simulations with and without the $\left(1-c_{\alpha} / c_{\alpha, \max }\right)$ relation in the definition of the effective solid-state diffusion coefficient (Eq. 21). All other parameters remain unchanged from Table IV. Experiments and simulations were conducted at a C/200 rate for electrodes comprised of $32 \mathrm{~nm}$ crystals.

Figure 10. Comparison of experimental data to multi-scale simulations with different values for the saturation concentration at which $\gamma$ starts to form from $\alpha\left(c_{\alpha}^{\gamma^{*}}\right)$. All other parameters remain unchanged from Table IV. Experiments and simulations were conducted at a C/200 rate for electrodes comprised of $32 \mathrm{~nm}$ crystals.

Figure 11. Voltage profiles during lithiation of electrodes containing a) 6 and b) $32 \mathrm{~nm} \mathrm{Fe} \mathrm{Fe}_{3}$ crystals at a C/200 rate. Simulations are shown on each figure for different rate constants for the formation of the $\gamma$ structure.

Figure 12. Predicted distributions of the volume fraction of $\alpha$ phase in the crystal at the outermost edge of the agglomerate. Distributions were obtained from simulations with a) 6 and b) $32 \mathrm{~nm} \mathrm{Fe} \mathrm{O}_{4}$ crystals. Simulations were conducted using the best fit values for $k_{\gamma}$ (i.e., $0.8 \times$ $10^{-3}$ and $2.5 \times 10^{-3}$ for 6 and $32 \mathrm{~nm}$ crystals, respectively). $x_{\text {avg }}$ label corresponds to the degree of lithiation in Figure 11, where $x$ refers to the average moles of lithium inserted into one mole of $\mathrm{Fe}_{3} \mathrm{O}_{4}$ electrode material. 
Figure A.1. Maximum voltage $\left(\mathrm{V}_{\max }\right)$ and voltage used to determine the open circuit potential of the supersaturated $\alpha$ phase $\left(\mathrm{V}_{\alpha}\right)$. All voltage obtained from recovery experiments. Data points represent the average value of the 6,8 ,and $32 \mathrm{~nm}$ experiments and the error bars represent the maximum and minimum deviation from average. 
Table I. Comparison of governing equations used in models with and without phase change. $r$ and $\bar{r}$ refer to units of distance in the agglomerate and crystal length-scales, respectively.

\section{$w / o \beta$ Formation [42]}

\section{$\mathbf{w} / \boldsymbol{\beta}$ Formation}

\begin{tabular}{|c|c|c|}
\hline $\begin{array}{l}\text { Mass } \\
\text { (agg.) }\end{array}$ & $\varepsilon \frac{\partial c_{a g g}}{\partial t}=\varepsilon D_{a g g} \frac{\partial^{2} c_{a g g}}{\partial r^{2}}+\frac{2 \varepsilon D_{a g g}}{r} \frac{\partial c_{a g g}}{\partial r}+\frac{a i_{r x n}}{F}$ & No change \\
\hline \multirow[t]{2}{*}{$\begin{array}{l}\text { Mass } \\
\text { (crystal) }\end{array}$} & $\frac{\partial c_{x}}{\partial t}=D_{x} \frac{\partial^{2} c_{x}}{\partial \bar{r}^{2}}+\frac{2 D_{x}}{\bar{r}} \frac{\partial c_{x}}{\partial \bar{r}}$ & $\left(1-\theta_{\beta}\right) \frac{\partial c_{\alpha}}{\partial t}=D_{x, e f f} \frac{\partial^{2} c_{\alpha}}{\partial \bar{r}^{2}}+\frac{2 D_{x, e f f}}{\bar{r}} \frac{\partial c_{\alpha}}{\partial \bar{r}}+\frac{\partial D_{x, e f f}}{\partial \bar{r}} \frac{\partial c_{\alpha}}{\partial \bar{r}}+\left(c_{\alpha}-c_{\beta}\right) \frac{\partial \theta_{\beta}}{\partial t}$ \\
\hline & - & $c_{x}=c_{\alpha} \theta_{\alpha}+c_{\beta} \theta_{\beta}$ \\
\hline Phase & - & $\frac{\partial \theta_{\beta}}{\partial t}=k_{\beta}\left(c_{\alpha}-c_{\alpha, s a t}^{\beta}\right) \theta_{\beta}^{2 / 3}\left(1-\theta_{\beta}\right)$ \\
\hline Charge & $a i_{r x n}=(1-\varepsilon) \sigma \frac{\partial^{2} \varphi_{1}}{\partial r^{2}}+\frac{2(1-\varepsilon) \sigma}{r} \frac{\partial \varphi_{1}}{\partial r}$ & No change \\
\hline Reaction & $i_{r x n}=i_{0}\left[\exp \left(\frac{\alpha_{a} F\left(\varphi_{1}-U\right)}{R_{G} T}\right)-\exp \left(\frac{-\alpha_{c} F\left(\varphi_{1}-U\right)}{R_{G} T}\right)\right]$ & No change \\
\hline & $i_{0}=F k_{r x n} c_{a g g}^{\alpha_{a}} c_{x}^{\alpha_{c}}\left(c_{x, \max }-c_{x}\right)^{\alpha_{a}}$ & $i_{0}=F k_{r x n} c_{a g g}^{\alpha_{a}} c_{\alpha}^{\alpha_{c}}\left(c_{\alpha, \max }-c_{\alpha}\right)^{\alpha_{a}}$ \\
\hline
\end{tabular}


Table II. Comparison of boundary conditions used in models with and without phase change. $r$ and $\bar{r}$ refer to units of distance in the agglomerate and crystal length-scales, respectively. $r_{\text {agg }}$ and $r_{x}$ are the radii of the agglomerate and crystals, respectively.

\begin{tabular}{lcc}
\hline & $\mathbf{w} / \mathbf{o} \boldsymbol{\beta}$ Formation [42] & $\mathbf{w} / \boldsymbol{\beta}$ Formation \\
\hline $\begin{array}{l}\text { Mass } \\
\text { (agg.) }\end{array}$ & $\frac{\partial c_{a g g}}{\partial r}=0$ at $r=0$ & No change \\
& $c_{a g g}=c_{0}$ at $r=r_{a g g}$ & \\
$\begin{array}{l}\text { Mass } \\
\text { (crystal) }\end{array}$ & $\frac{\partial c_{x}}{\partial \bar{r}}=0$ at $\bar{r}=0$ & $\frac{\partial c_{\alpha}}{\partial \bar{r}}=0$ at $\bar{r}=0$ \\
& $-D_{x} \frac{\partial c_{x}}{\partial \bar{r}}=\frac{i_{r x n}(r)}{n F}$ at $\bar{r}=r_{x}$ & $-D_{x, e f f} \frac{\partial c_{\alpha}}{\partial \bar{r}}=\frac{\theta_{\alpha} i_{r x n}(r)}{n F}$ at $\bar{r}=r_{x}$ \\
Charge & $\frac{\partial \varphi_{1}}{\partial r}=0$ at $r=0$ & No change \\
& $\frac{\partial \varphi_{1}}{\partial r}=\frac{i_{a p p} \rho_{F e_{3} O_{4}} r_{a g g}}{3 \sigma}$ at $r=r_{a g g}$ & \\
\hline
\end{tabular}


Table III. Parameters used in simulations with and without phase change from $\alpha-\mathrm{Li}_{\mathrm{X}} \mathrm{Fe}_{3} \mathrm{O}_{4}$ to $\beta$ $\mathrm{Li}_{4} \mathrm{Fe}_{3} \mathrm{O}_{4}$.

\begin{tabular}{llcc}
\hline & & \multicolumn{2}{c}{ Value } \\
\cline { 3 - 4 } \multicolumn{1}{c}{ Symbol } & Description & w/o $\boldsymbol{\beta}$ [42] & w/ $\boldsymbol{\beta}$ \\
\hline$D_{a g g}$ & Diffusion in agglomerate $\left(\mathrm{cm}^{2} \mathrm{~s}^{-1}\right)^{\mathrm{a}}$ & $2.3 \times 10^{-13}$ & $2.6 \times 10^{-13}$ \\
$D_{x}$ or $D_{x, \alpha}$ & Diffusion in crystal $\left(\mathrm{cm}^{2} \mathrm{~s}^{-1}\right)^{\mathrm{a}}$ & $2.0 \times 10^{-18}$ & $1.25 \times 10^{-18}$ \\
$c_{x, \max }$ or $c_{\alpha, \max }$ & Max concentration in crystal $\left(\mathrm{mol} \mathrm{cm}^{-3}\right)^{\mathrm{b}}$ & $1.79 \times 10^{-1}$ & $1.79 \times 10^{-1}$ \\
$k_{\beta, 1}$ & $\beta$ phase rate constant $1\left(\mathrm{~cm}^{3} \mathrm{~mol}^{-1} \mathrm{~s}^{-1}\right)^{\mathrm{a}}$ & - & $1.0 \times 10^{-5}$ \\
$k_{\beta, 2}$ & $\beta$ phase rate constant $2\left(\mathrm{~cm}^{3} \mathrm{~mol}^{-1}\right)^{\mathrm{a}}$ & - & 60 \\
$c_{\alpha, \text { sat }}^{\beta}$ & Saturation concentration of $\alpha\left(\mathrm{mol} \mathrm{cm}^{-3}\right)^{\mathrm{b}}$ & - & $2.24 \times 10^{-2}$ \\
$c_{\beta}$ & Concentration in $\beta(\mathrm{mol} \mathrm{cm})^{-3}$ & - & $8.94 \times 10^{-2}$ \\
\hline
\end{tabular}

${ }^{\mathrm{a}}$ fit to experimental data

bobtained from analysis of voltage recovery 
Table IV. Parameters used in simulations with phase change from $\alpha-\mathrm{Li}_{x} \mathrm{Fe}_{3} \mathrm{O}_{4}$ to $\gamma-\left(4 \mathrm{Li}_{2} \mathrm{O}+3\right.$ $\mathrm{Fe})$.

\begin{tabular}{llc}
\hline \multicolumn{1}{c}{ Symbol } & Description & Value \\
\hline$D_{a g g}$ & Diffusion in agglomerate $\left(\mathrm{cm}^{2} \mathrm{~s}^{-1}\right)^{\mathrm{a}}$ & $2.6 \times 10^{-13}$ \\
$D_{x, \alpha}$ & Diffusion in $\alpha$ phase $\left(\mathrm{cm}^{2} \mathrm{~s}^{-1}\right)^{\mathrm{a}}$ & $1.25 \times 10^{-18}$ \\
$D_{x, \gamma}$ & Diffusion in $\gamma$ phase $\left(\mathrm{cm}^{2} \mathrm{~s}^{-1}\right)^{\mathrm{a}}$ & $5.0 \times 10^{-17}$ \\
$c_{\alpha, \max }$ & Max concentration in $\mathrm{crystal}\left(\mathrm{mol} \mathrm{cm}^{-3}\right)^{\mathrm{b}}$ & $1.79 \times 10^{-1}$ \\
$k_{\gamma}(6 \mathrm{~nm})$ & $\gamma$ phase rate constant $\left(\mathrm{cm}^{3} \mathrm{~mol}^{-1} \mathrm{~s}^{-1}\right)^{\mathrm{a}}$ & $0.8 \times 10^{-3}$ \\
$k_{\gamma}(32 \mathrm{~nm})$ & $\gamma$ phase rate constant $\left(\mathrm{cm}^{3} \mathrm{~mol}^{-1} \mathrm{~s}^{-1}\right)^{\mathrm{a}}$ & $2.5 \times 10^{-3}$ \\
$c_{\alpha, s a t}^{\gamma}$ & Saturation concentration of $\alpha\left(\mathrm{mol} \mathrm{cm}^{-3}\right)^{\mathrm{a}}$ & $8.94 \times 10^{-2}$ \\
$c_{\gamma}$ & Concentration in $\gamma(\mathrm{mol} \mathrm{cm})^{-3}$ & $1.79 \times 10^{-1}$ \\
\hline
\end{tabular}

afit to experimental data

bobtained from analysis of voltage recovery 
Table A.1. Parameters determined for the equation of the open circuit potential of the $\alpha$ phase derived from the Redlich-Kister expansion.

\begin{tabular}{cc}
\hline Parameter & Value \\
\hline$N$ & 7 \\
$U_{\text {ref }}$ & 1.518 \\
$A_{0}$ & -0.6472 \\
$A_{1}$ & 0.1283 \\
$A_{2}$ & 0.3218 \\
$A_{3}$ & 0.1577 \\
$A_{4}$ & -0.6670 \\
$A_{5}$ & 0.3445 \\
$A_{6}$ & 0.1228 \\
$A_{7}$ & -0.1405 \\
\hline
\end{tabular}




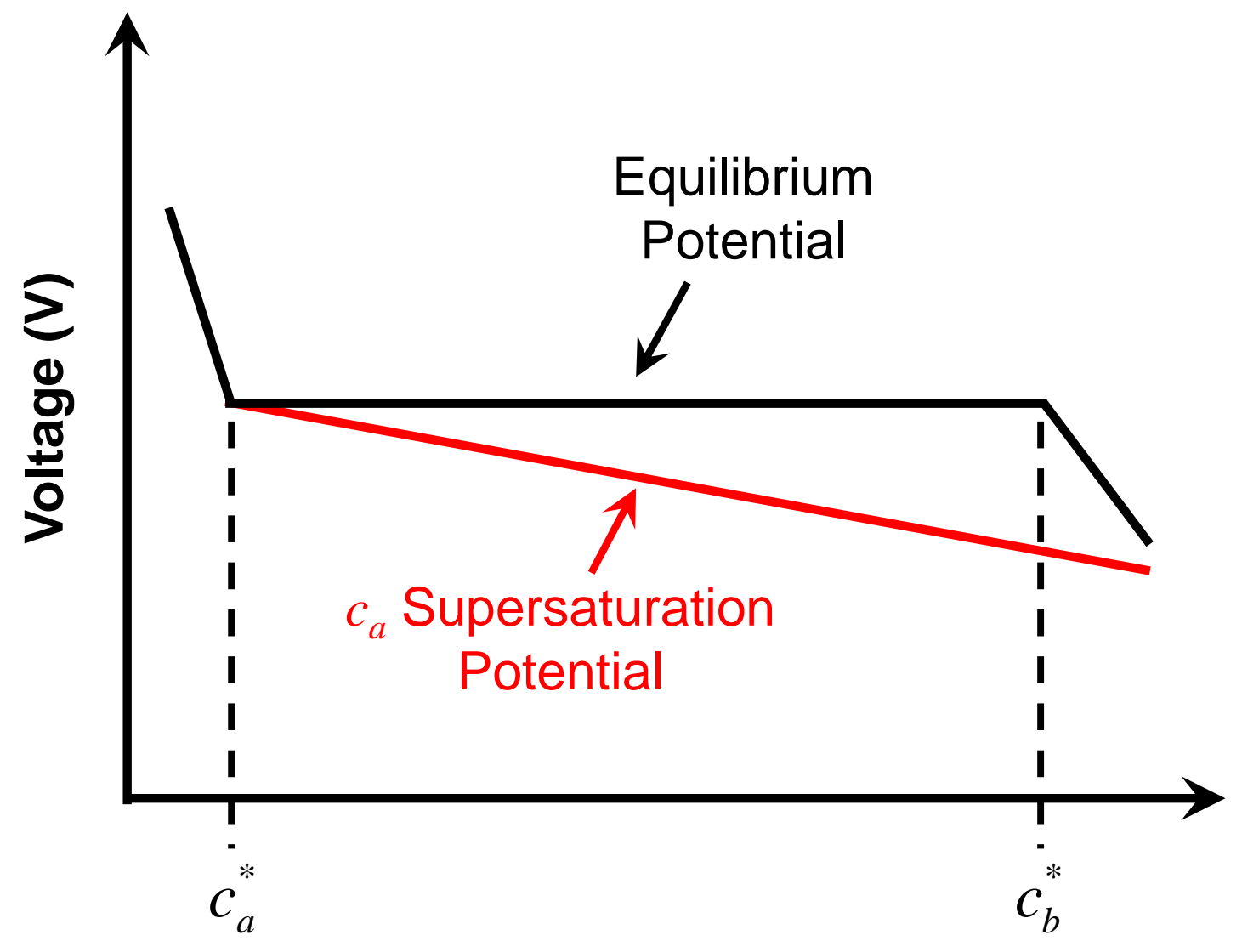

\section{Total solid-state lithium concentration}

Figure 1. Schematic of the equilibrium potential and supersaturation potential during phase change of a host material from phase $a$ (at a solid-state lithium concentration of $c_{a}$ ) to phase $b$ (at a solid-state lithium concentration of $c_{b}{ }^{*}$ ). 
a)

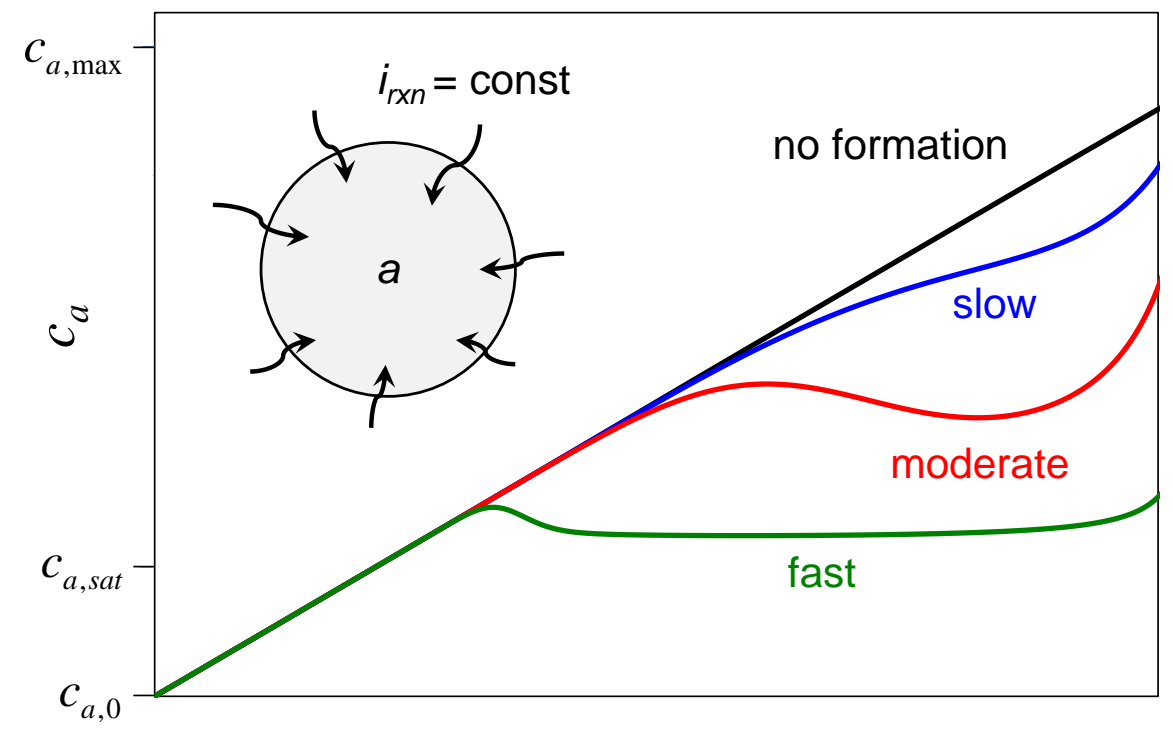

b)

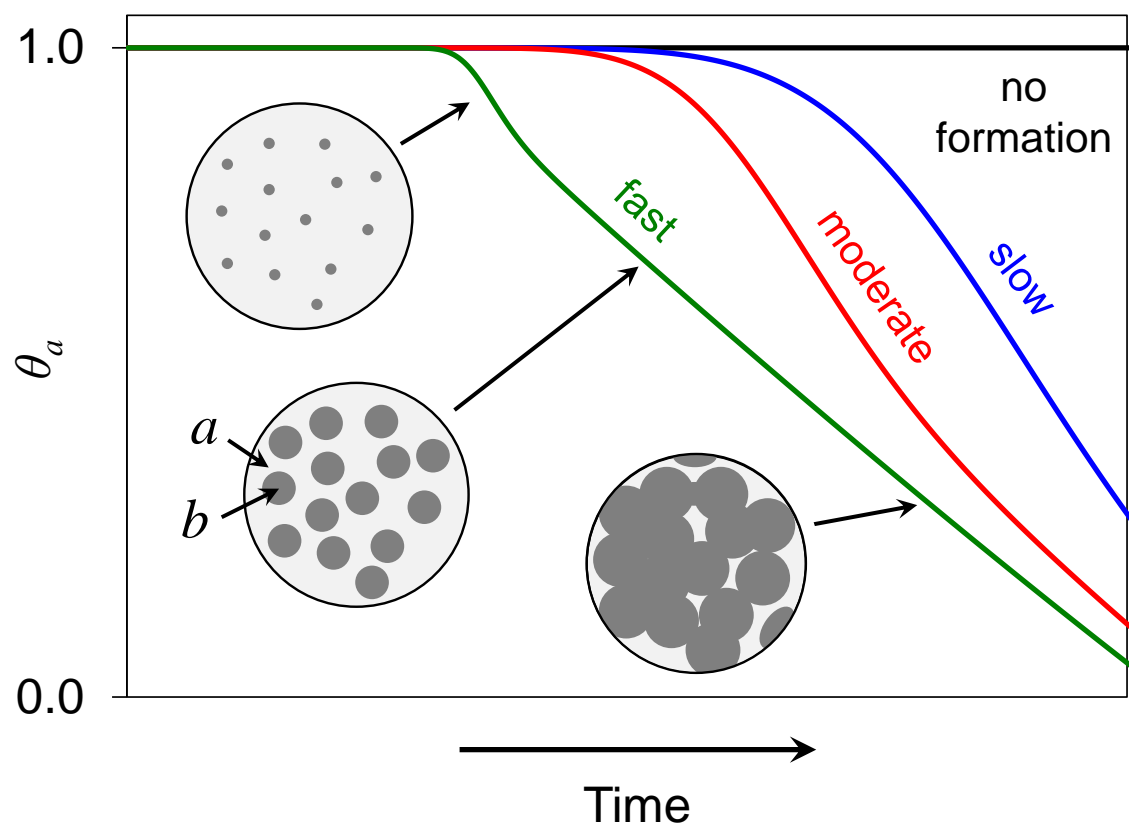

Figure 2. Generic results for a particle undergoing phase change from phase $a$ to $b$. a) Concentration of solid-state lithium in phase $a\left(c_{a}\right)$ and b) volume fraction of phase $a\left(\theta_{a}\right)$ during uniform lithiation of a particle at a constant reaction rate. Diagrams show how $c_{a}$ and $\theta_{a}$ are impacted by the slow, moderate, and fast formation of phase $b$ (from $a$ ) as described in Eq. 1 . 


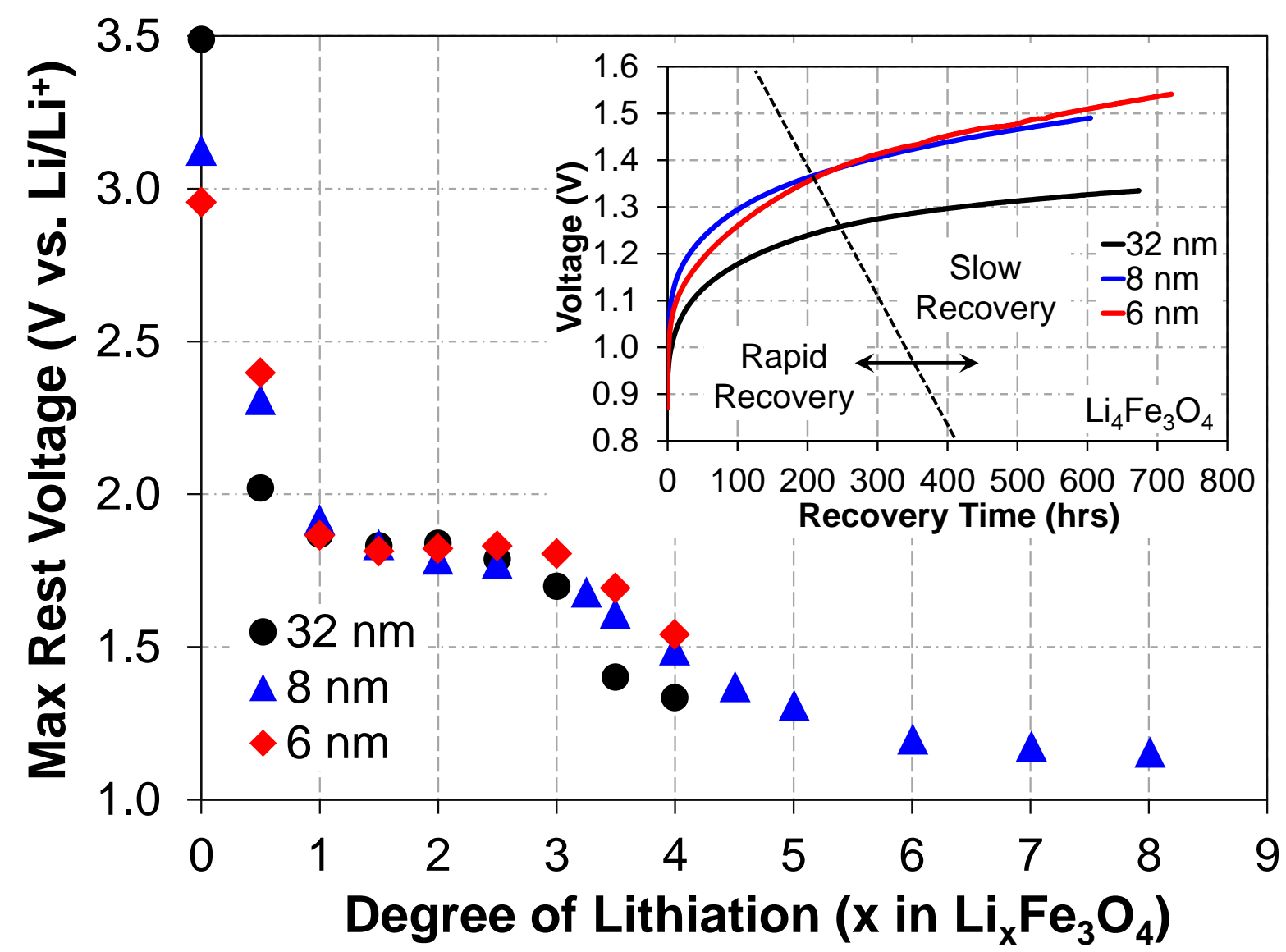

Figure 3. Maximum voltage during recovery at open circuit for up to 30 days after lithiation to a set amount of $x$ in $\mathrm{Li}_{x} \mathrm{Fe}_{3} \mathrm{O}_{4}$. Inset: Experimental data for voltage recovery after lithiation to $x=4$ for $x$ in $\mathrm{Li}_{\mathrm{x}} \mathrm{Fe}_{3} \mathrm{O}_{4}$. Voltage recovery data sectioned into an initial, rapid recovery attributed to the relaxation of concentration distributions on the agglomerate and crystal length-scales and a later, slow recovery attributed to the formation of the $\beta$ phase from the $\alpha$ phase. 


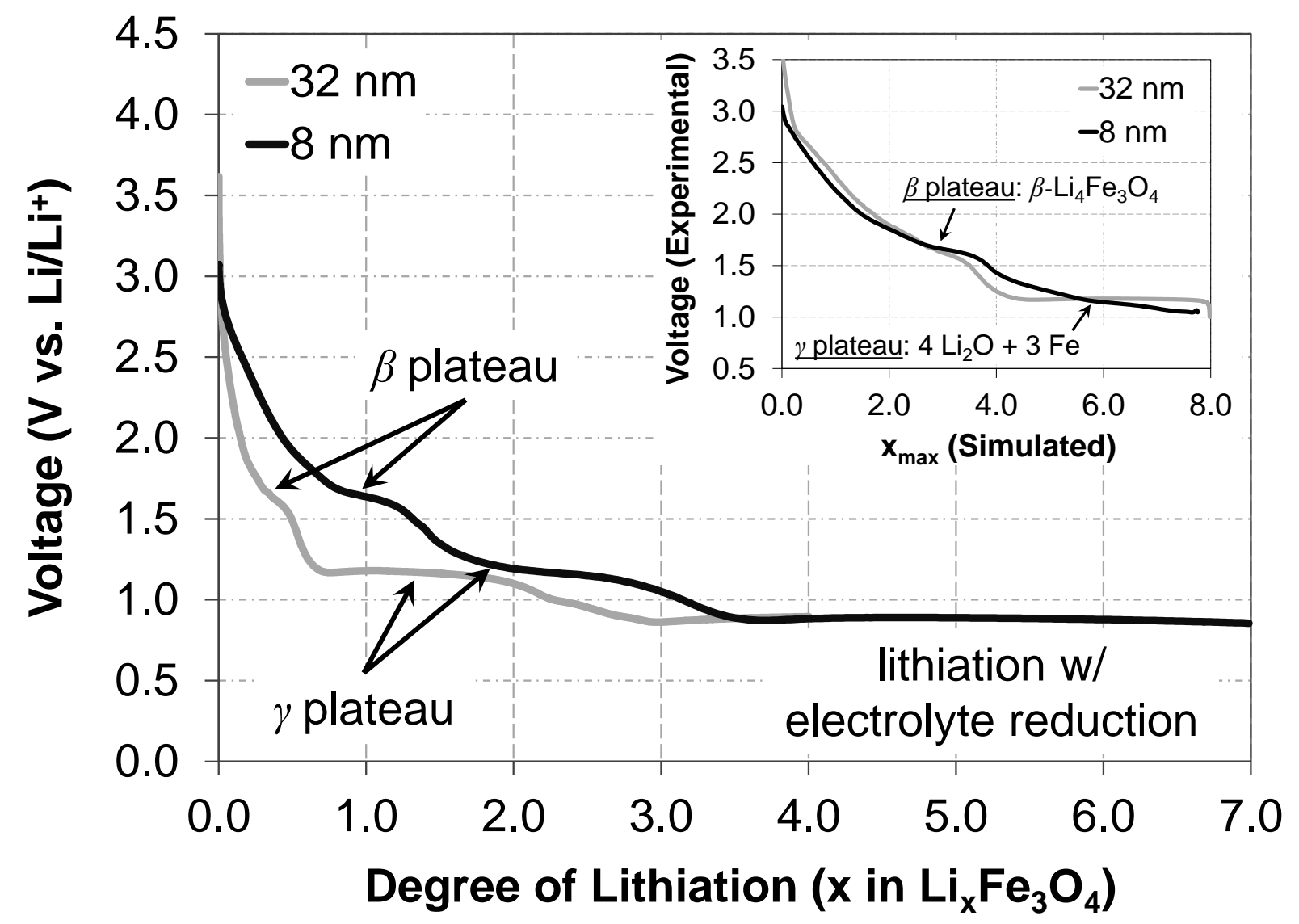

Figure 4. Lithiation of pristine electrodes comprised of 8 and $32 \mathrm{~nm}$ crystals at a C/200 rate. Inset: Plot of experimental voltage vs. maximum solid-state concentration predicted by model during lithiation (see Section 4.3 for model details). 

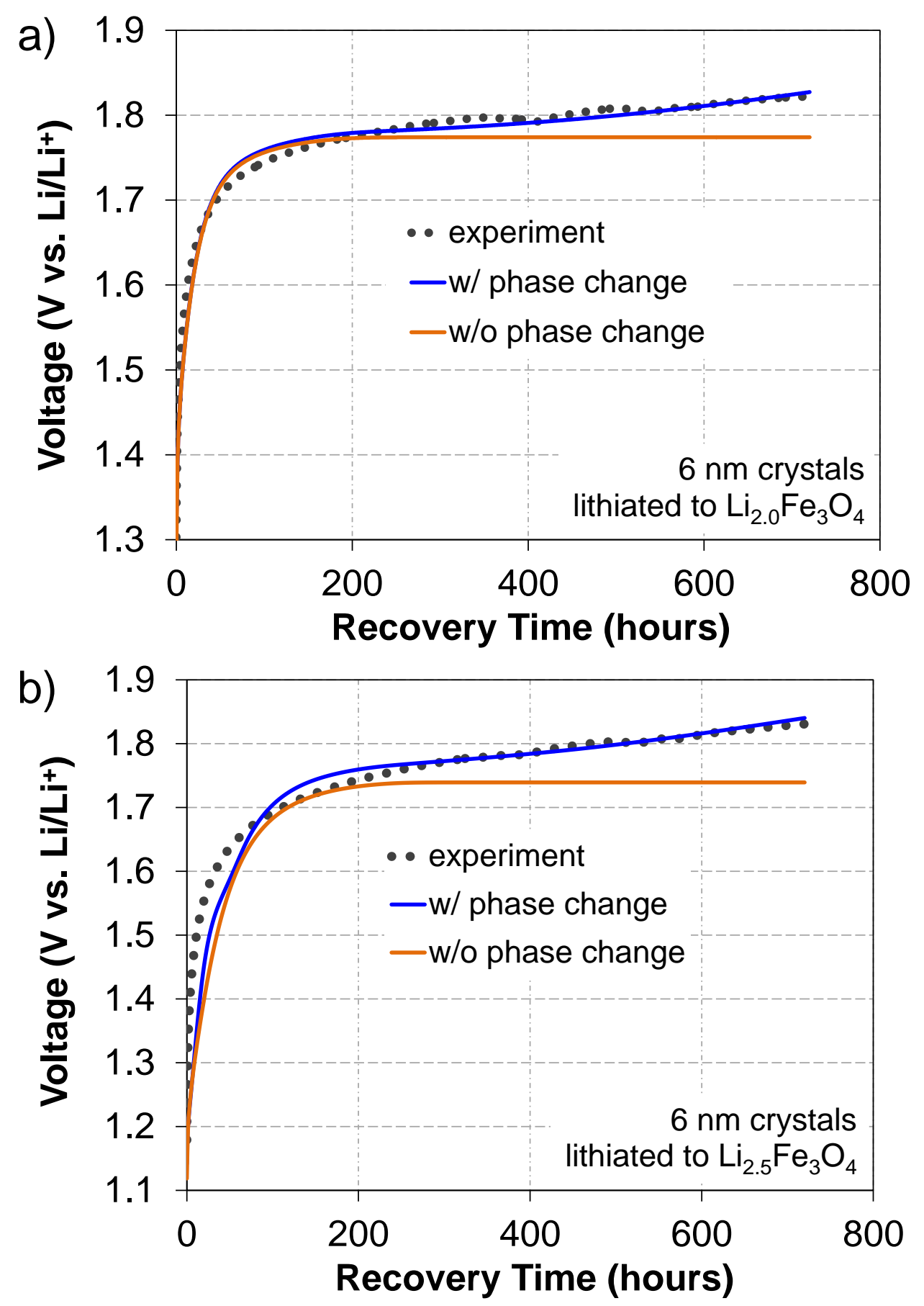

Figure 5. Comparison of experimental voltage recovery data to simulated results from models with and without phase change from $\alpha$ to $\beta$. Data is shown for recovery after lithiation to average concentrations of a) $x=2$ and b) $x=2.5 \mathrm{in}_{\mathrm{Li}} \mathrm{Fe}_{3} \mathrm{O}_{4}$ at a C/200 rate. 


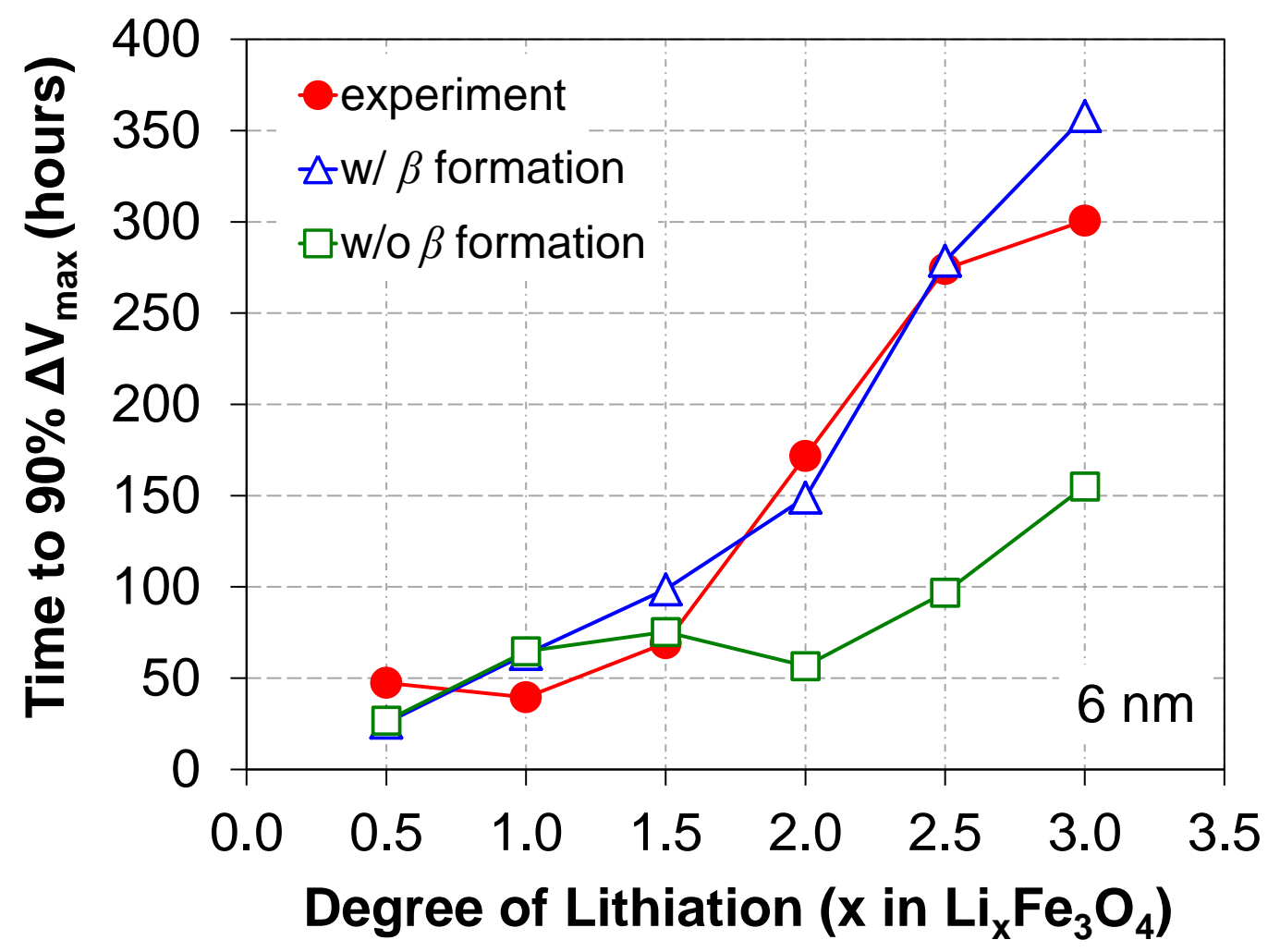

Figure 6. Rise time during voltage recovery, which is defined as the time required to reach $90 \%$ of the maximum voltage. 


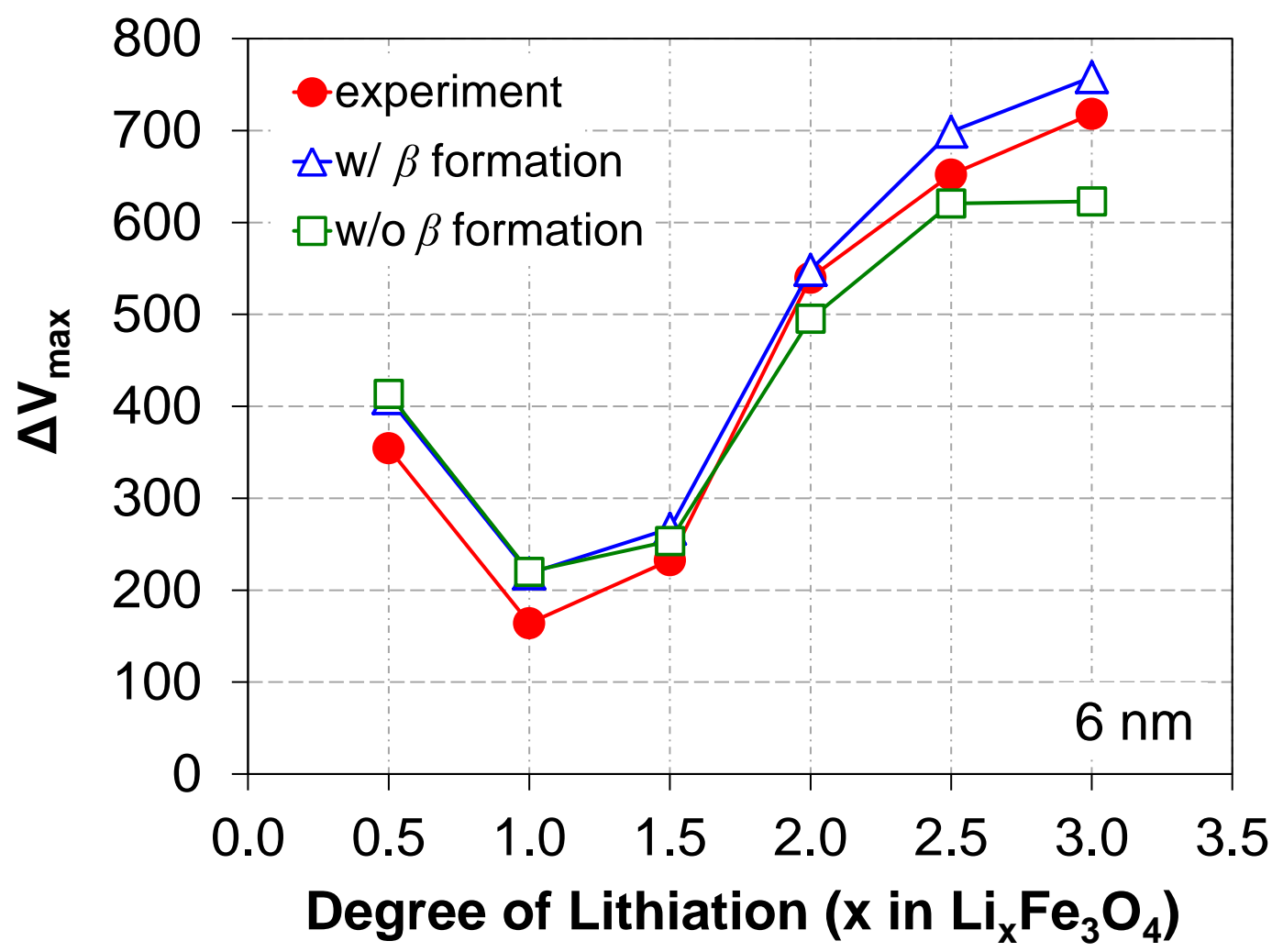

Figure 7. Maximum change in voltage during voltage recovery. 


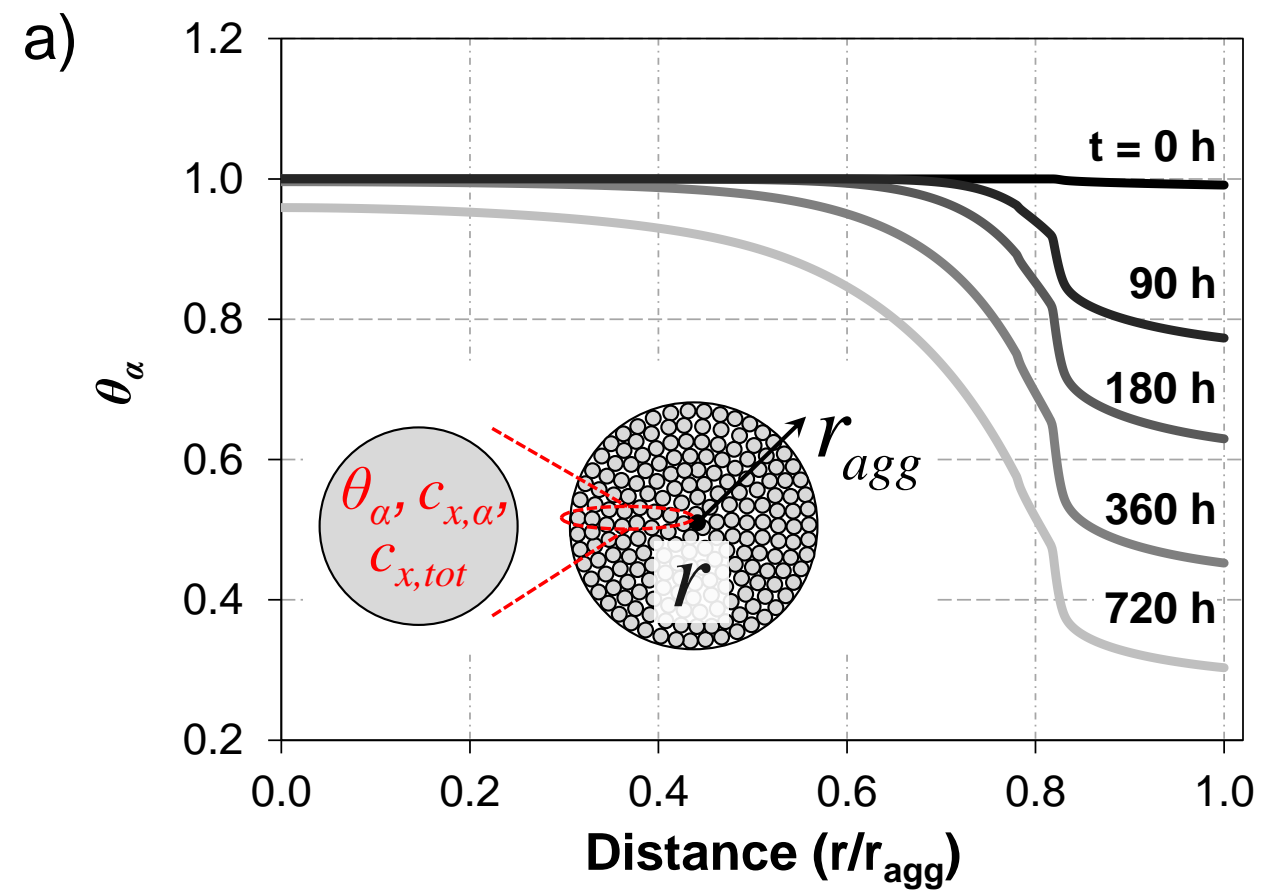

b)

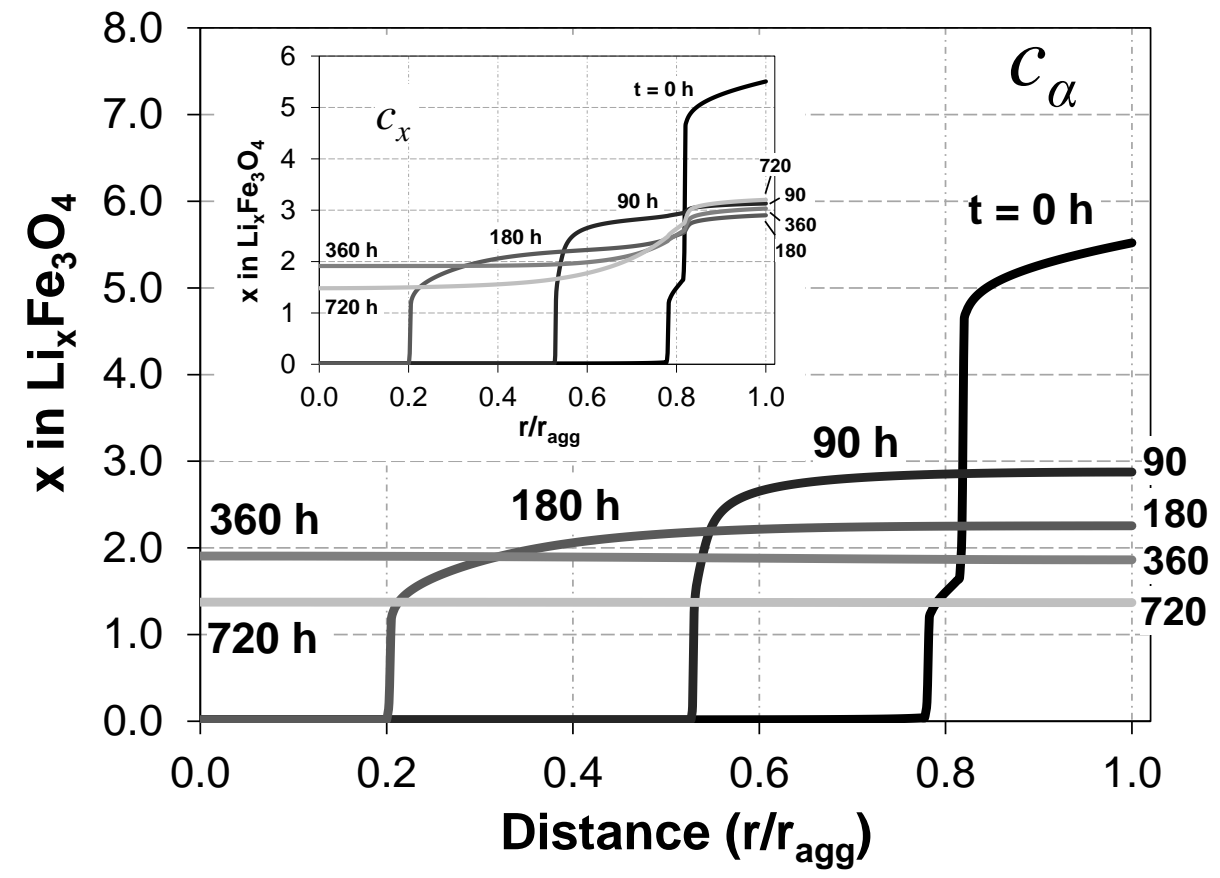

Figure 8. Distributions of a) $\theta_{\alpha}$ and b) $c_{\alpha}$ within agglomerate during recovery of an agglomerate comprised of $6 \mathrm{~nm}$ crystals after a lithiation to an average concentration of $x=2.5$ in $\mathrm{Li}_{x} \mathrm{Fe}_{3} \mathrm{O}_{4}$. Times are reported with respect to the start of recovery. Inset in b): Distribution of the total solidstate lithium concentration in both the $\alpha$ and $\beta$ phases. 


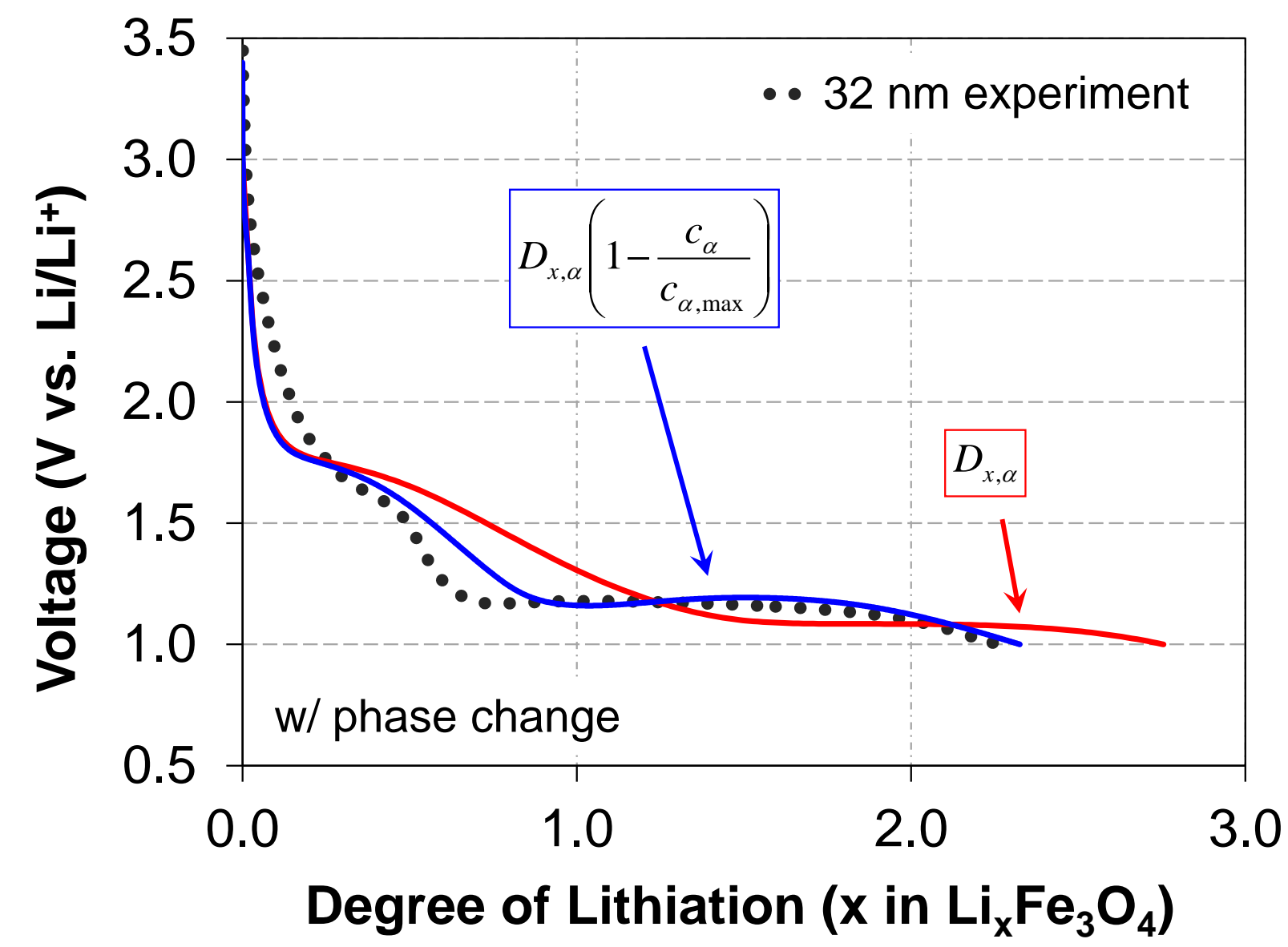

Figure 9. Comparison of experimental data to simulations with and without the $\left(1-c_{\alpha} / c_{\alpha, \max }\right)$ relation in the definition of the effective solid-state diffusion coefficient (Eq. 21). All other parameters remain unchanged from Table IV. Experiments and simulations were conducted at a $\mathrm{C} / 200$ rate for electrodes comprised of $32 \mathrm{~nm}$ crystals. 


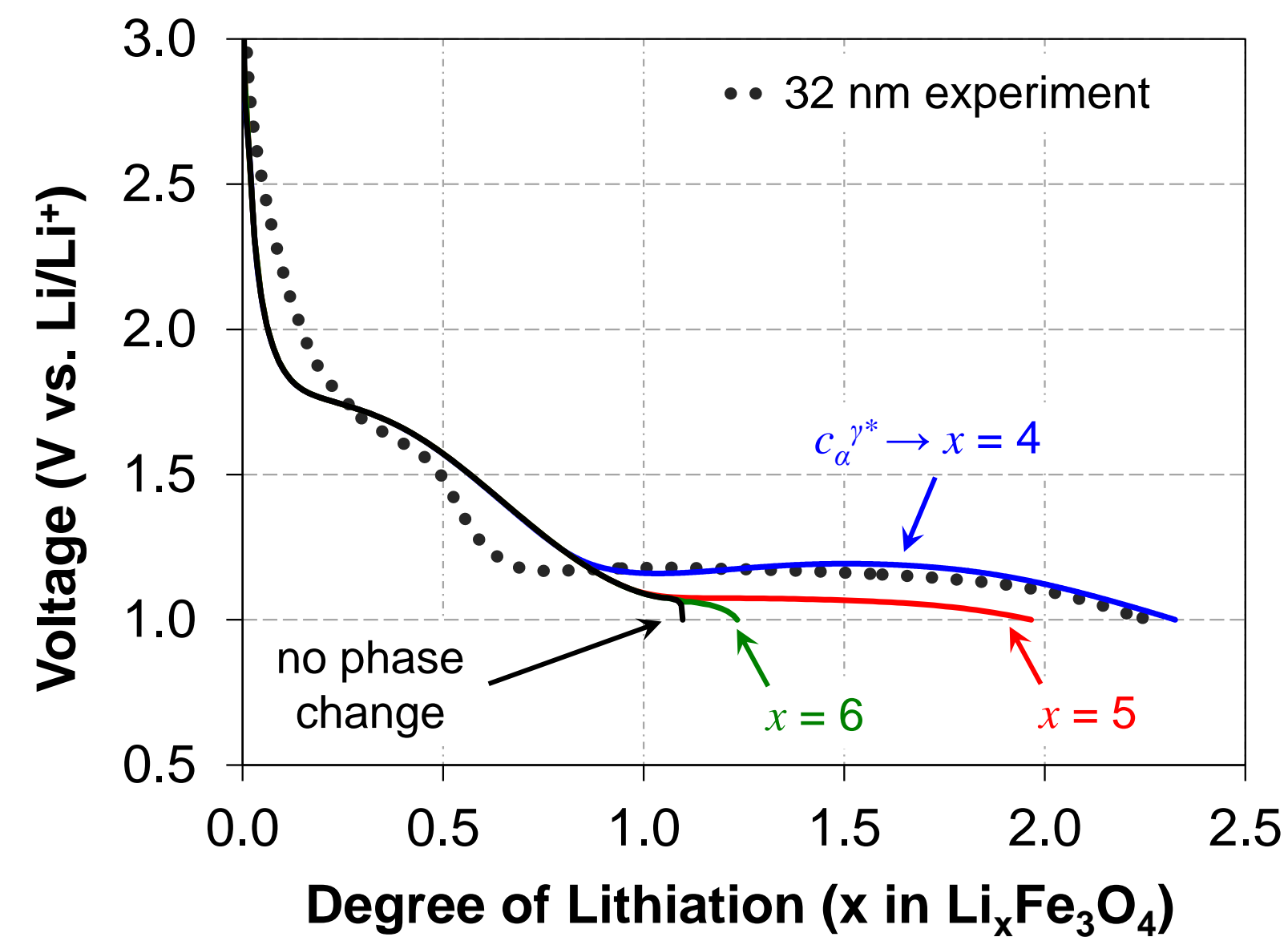

Figure 10. Comparison of experimental data to multi-scale simulations with different values for the saturation concentration at which $\gamma$ starts to form from $\alpha\left(c_{\alpha}{ }^{\gamma^{*}}\right)$. All other parameters remain unchanged from Table IV. Experiments and simulations were conducted at a C/200 rate for electrodes comprised of $32 \mathrm{~nm}$ crystals. 
a)

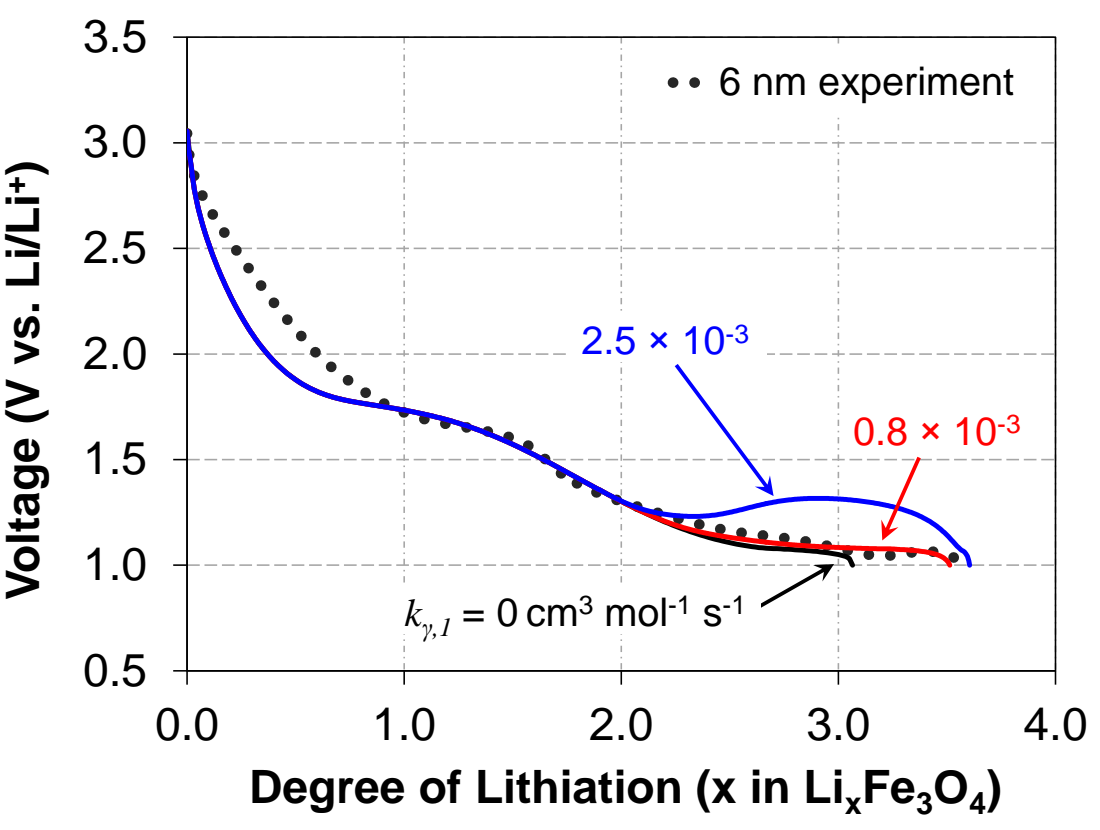

b)

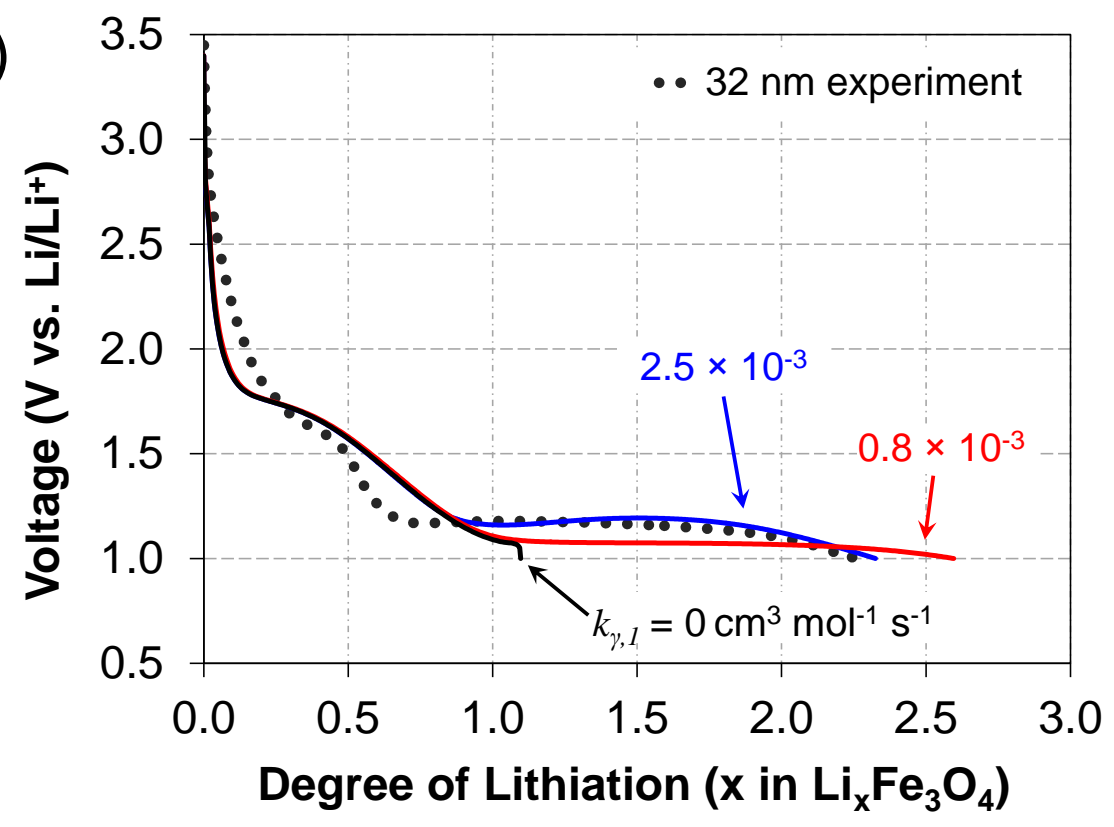

Figure 11. Voltage profiles during lithiation of electrodes containing a) 6 and b) $32 \mathrm{~nm} \mathrm{Fe}_{3} \mathrm{O}_{4}$ crystals at a C/200 rate. Simulations are shown on each figure for different rate constants for the formation of the $\gamma$ structure. 

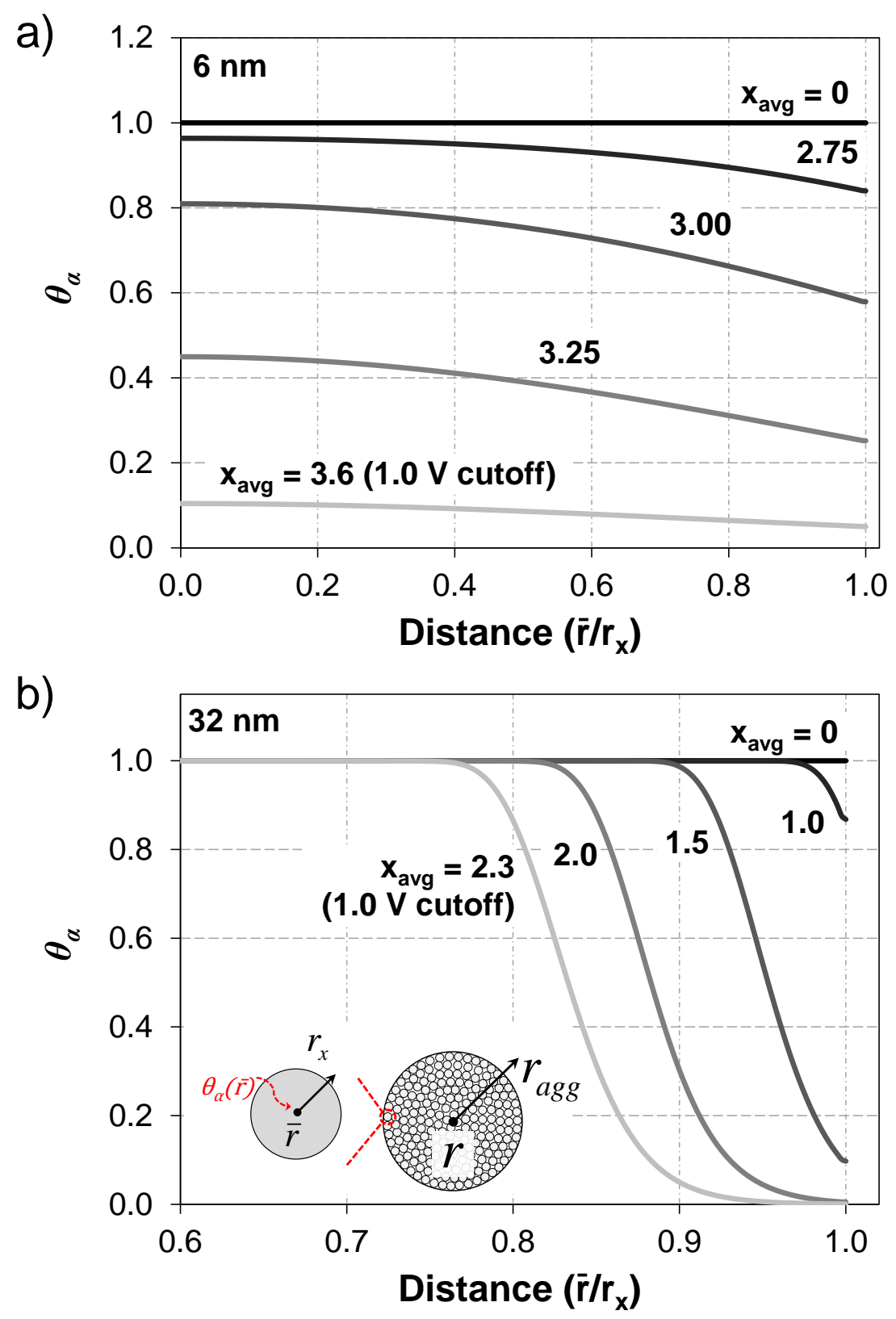

Figure 12. Predicted distributions of the volume fraction of $\alpha$ phase in the crystal at the outermost edge of the agglomerate. Distributions were obtained from simulations with a) 6 and b) $32 \mathrm{~nm} \mathrm{Fe} \mathrm{O}_{4}$ crystals. Simulations were conducted using the best fit values for $k_{y}$ (i.e., $0.8 \times$ $10^{-3}$ and $2.5 \times 10^{-3}$ for 6 and $32 \mathrm{~nm}$ crystals, respectively). $x_{\text {avg }}$ label corresponds to the degree of lithiation in Figure 11, where $x$ refers to the average moles of lithium inserted into one mole of $\mathrm{Fe}_{3} \mathrm{O}_{4}$ electrode material. 


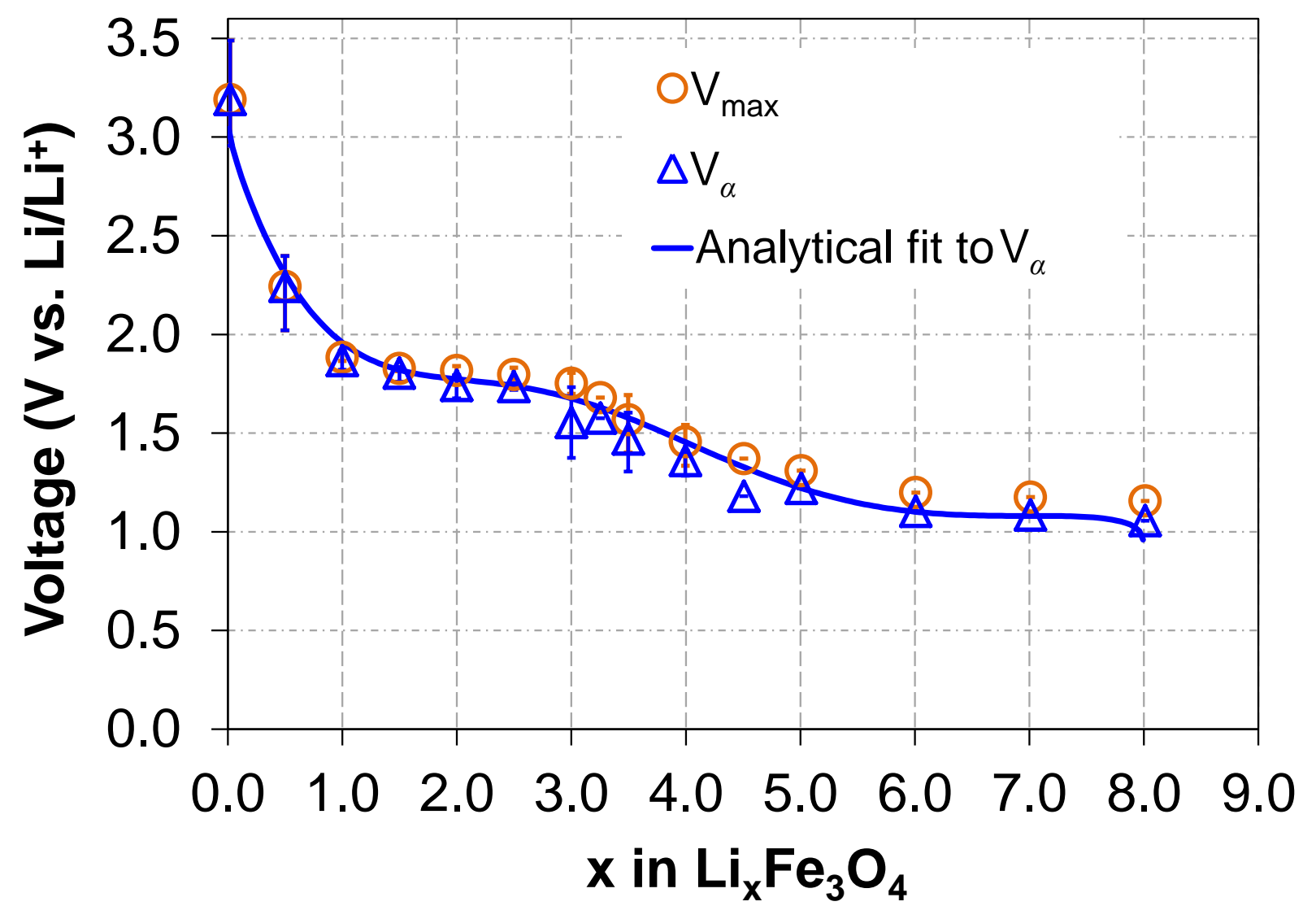

Figure A.1. Maximum voltage $\left(\mathrm{V}_{\max }\right)$ and voltage used to determine the open circuit potential of the supersaturated $\alpha$ phase $\left(\mathrm{V}_{\alpha}\right)$. All voltage obtained from recovery experiments. Data points represent the average value of the 6,8 ,and $32 \mathrm{~nm}$ experiments and the error bars represent the maximum and minimum deviation from average. 